University of Rhode Island

DigitalCommons@URI

Open Access Master's Theses

1977

\title{
THE EFFECT OF CAFFEINE ON CARDIAC VULNERABILITY TO TACHYARRHYTHMIA IN THE RAT
}

Fred A. Rotenberg

University of Rhode Island

Follow this and additional works at: https://digitalcommons.uri.edu/theses

\section{Recommended Citation}

Rotenberg, Fred A., "THE EFFECT OF CAFFEINE ON CARDIAC VULNERABILITY TO TACHYARRHYTHMIA IN THE RAT" (1977). Open Access Master's Theses. Paper 221.

https://digitalcommons.uri.edu/theses/221

This Thesis is brought to you for free and open access by DigitalCommons@URI. It has been accepted for inclusion in Open Access Master's Theses by an authorized administrator of DigitalCommons@URI. For more information, please contact digitalcommons-group@uri.edu. 


\author{
THE EFFECT OF CAFFEINE. \\ ON CARDIAC VULNERABILITY \\ TO TACHYARRHYTHMIA IN THE RAT \\ BY \\ FRED A. ROTENBERG
}

A THESIS SUBMITTED IN PARTIAL FULFILLMENT OF THE RERUIREMENTS FOR THE DEGREE OF MASTER OF SCIENCE

IN

PHARMACOLOGY AND TOXICOLOGY

UNIVERSITY OF RHODE ISLAND

1977 


\section{PAASTER OF SCIEHCE THESIS \\ OF}

FRED ABRAHAM ROTENBERG

Approved

Thes is Committee Major Professor

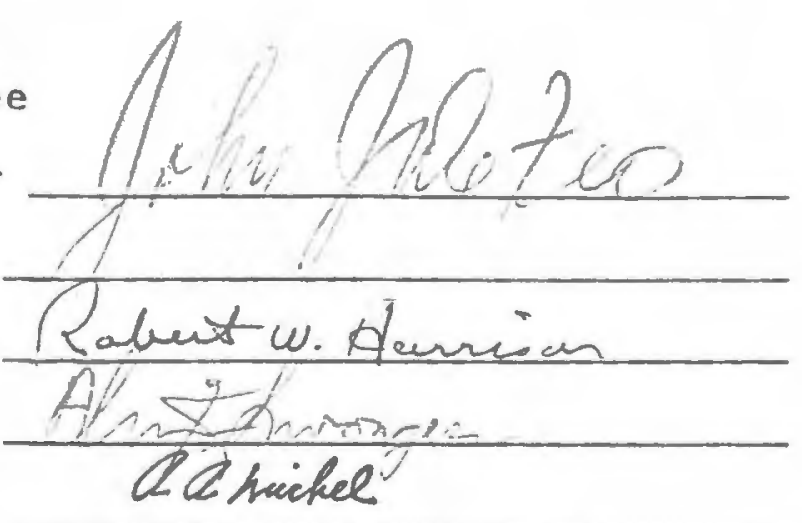

Dean of the Graduate School

UNIVERSITY OF RHODE ISLAND

1977 


\section{ABSTPACT}

Ventricular fibrillation is one of the primary causes of early sudden death associated with myocardial infarction (Lown et al.e 1969). Although Bellet et al. 1972) have shown that caffeine infusion increases susceptiblitity to ventricular fibrillation in the dog, the question of the effect of dally caffeine consumption on cardiac vulnerability remains unanswered.

Retrospective clinical studies examining the association of coffee consumption on heart disease cloud the long term effect of caffeine on cardlac vulnerablility to arrhythmia in that they are often complicated by differences in each group's level of cigarette smoking, blood pressure, body weight, etc. In this study the effects of long term caffeine administration on the susceptibility of the heart to ventricular fibrlllation was examined.

Vulnerability to cardiac arrhythmia in the adult male rat was determined by measuring the ventricular tachycardia threshold (VTT). The VTT was used as an index of the vulnerabllity of larger hearts to fibrillation. It was defined as the minimum current necessary to generate sustained ventricular tachycardia, and was tested by applying trains of pulses directly to the right ventricular epicardium through bipolar platinum 
electrodes. The train consisted of constant current, 70 $\mathrm{Hz}$, monophasic, 2 msec rectangular pulses. It was delivered 10 msecs after the right atrial pacing pulse and lasted 90 msecs so as to end before the apex of the $T$ wave of the electrocardlogram.

In rats recelving a single oral injection of caffeine ( 30 or $90 \mathrm{mg} / \mathrm{kg}$ ) VTT was 25 per cent lower than the VTT of water injected rats $(p<0.05)$. The oral injection of water reduced VTT by $35 \%$ when compared with untreated controls. The caffelne related reduction was in addition to that associated with the injection process. Corresponding tachycardla suggested that the injection process, in addition to the caffeine administration, was associated with sympathetic discharge which presumably mediated the reduction in threshold.

Dally oral treatment with caffeine (in the same doses) for $2,4,8$ or 10 weeks caused a time related reversal of the acute effects of caffelne injection. Following 2 or 4 weeks of treatment, acute caffeine administration no longer was assoclated with a reduction in VTT. After 8 or 10 weeks of chronic caffeine administration, acute caffeine injection was assoclated with thresholds more than twice as great as water treated controls. This relative increase in VTT following chronic caffeine was dose dependent. The increase in VTT following chronlc caffeine administration was the same magnitude whether the rat was injected just prior to VTT 
testing with water or with caffeine.

Caffeine injection $(90 \mathrm{mg} / \mathrm{kg} / \mathrm{day}, \mathrm{p.0.})$ for a period of 10 weeks attenuated the maximal chronotropic effect of isoproterenol. This result suggested a reduction in cardiac beta adrenergic receptor concentration. The reduction in the vulnerability of the rat ventricle to tachyarrhythmia assoclated with chronic caffeine administration, may be due to the same reduction In the cardiac adrenergic receptor population. 


\section{ACKNOWLEDGEMENTS}

The author conveys his sincere appreciation to the faculty and his fellow graduate students of the Department of Pharmacology and Toxicology. Their support, guidance and friendship throughout this study were invaluable. Specific thanks are expressed to Drs. De Feo, Swonger and Harrison, Drs. Robert Numan, Gerald Gianutsos and Richard Drawbaugh, Mssrs. Martin Hynes, Steven Miksic and Ms. Jeannee K. Yermakoff.

The author would like to take this opportunity to also express his gratitude to the following people who helped $\mathrm{him}$ in various stages of this research. The advice of Dr. Richard verpier concerning threshold testing is gratefully acknowledged. The editorial assistance of Dr. Charles Blatt is appreciated. The assistance of Mssrs. John Caporal and Walter Kuklinski in the design and construction of the electrical components is also acknowledged. The author thanks Ms. Jean Mackie, R.N., Mr. Andrew Bellenkes and Mrs. Naydalls Wood for help with graphics and Ms. Nancy Ahonen and Wendy Mlchael for secretarial assistance.

Finally, I am most indebted to Ms. Sally I. Sherwin for her unwavering faith, support and love. The completion of this thesis is a tribute to her inspiration. 
ABSTRACT . . . . . . . . . . . . . . . i

ACKNOWLEDGEMENTS .................. . iv

TABLE OF CONTENTS. . . . . . . . . . . . . v

LIST OF TABLES .................. . . . . . .

LIST OF FIGURES................ VIII

INTRODUCTION . . . . . . . . . . . . . . . I

REVIEW OF THE LITERATURE ............ 4

Fibrillation. . . . . . . . . . 5

Vulnerability to Ventricular fibriliation: : : 7

A. Excitable Stimulus.......... 8

B. Factors Favoring Reentry. . . . . . . 10

C. Critical Myocardial Mass. . . . . . . 14

Assessment of Vulnerabillty to Fibrillation. . I 15

A. Nonelectrical Techniques........ 16

B. Electrical Fibrillation

Threshold Techniques ........... 21

1) The single shock method ........ . 25

2) The alternating current method.... . 30

3) The train of pulses method....... 34

Factors known To Affect Vulnerability. . . . . 37

Caffeine - Its Relevant Pharmacology. . . . . 42

A. Chemistry, Source and Pharmacokinetics. . 42

B. Pharmacologic Activity. ........ 47

1) Central nervous system. . . . . . 4 47

2) Peripheral nervous system ...... 50

3) Cardiovascular system . . . . . . 52

4) Effects on ventricular vulnerability. . 54

C. Molecular Mechanisms of Action..... 57

D. Caffeine Consumption, Tolerance

and Therapeutic Use . . . . . . . . 59

METHODS. •................. 61

Experimental Design and General Methods... 61

A. Basic Design of Experiments . . . . . . 61

B. Subjects, Animal Care and Drug Treatment. . 62

Ventricular Threshold Measurement ....... 65

A. Surgical Procedure. . . . . . . . 65 
B. Equipment Design ......... . . 65

C. Stimulation Protocol......... 73 Effect of Chronic Caffeine Treatment On

Cardiac Sensitivity To I soproterenol. . . . . 77 Stat istical Methods ........... . 78 Justification of Methods. . . . . . . 79

A. VTT as an Estimate of Vulnerability to VF . 79

B. Use of the Rat as the Experimental Species. 81

C. Caffeine Administration ....... . 82

D. Isoproterenol Dose Response Curves... . 83

E. Statistical Analysis......... 84

RESULTS. . . . . . . . . . . . 86

Introductory Remarks. . . . . . . . . 86

Effect of Acute Caffeine Treatment on VTT . : 89

Effect of Daily Caffeine Treatment On VTT . . . 92

A. Chronic Caffeine Treatment

Plus Acute Caffeine Challenge.... . . . 92

B. Chronic Caffeine Treatment

Plus Acute Water Challenge........100 Effect of Chronic Caffeine Treatment on

Isoproterenol Induced Tachycardia .......101

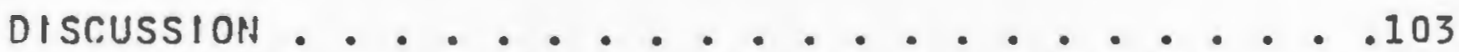

SUMMARY AND CONCLUSIOHS. . . . . . . . . . . . .

REFERENCES . . . . . . . . . . . . . . . . . .

APPENDIX . . : . . . . . . . . . . . .125 
Drugs Which Reduce

Vulnerability to Ventricular Fibrillation

11

Physiologic Interventions Which Reduce

Vulnerability To Ventricular Fibrillation

41

111

Interventions Which increase

Vulnerability To Ventricular Fibrillation

IV

Results of Analysis of Variance

of VTT Data

98

v

Summary of VTT Data and

LSD Test of Significant Differences 


\section{LIST OF FIGURES}

FIGURE

PAGE

Block Diagram of Electrical

Components Used in VTT Testing

2 .

Wiring Diagram of Electrical

Components Used in VTT Testing

3.

Wiring Dlagram of Constant Current Converting and Current Measuring Junction Boxes

4.

Wiring Diagram of Semiautomatic Shut off Device

5.

Localization of the Test Train Within the Cardiac Cycle

6.

Electrocardiographic and Hemodynamic Documentation of VT

7.

Progressive Elevation in VTT

Following Anesthesia

8.

Correlation of Initial VTT with

Time After Anesthesia

9.

Effect of Acute Caffeine

injection on VTT 
10.

Reversal of the Effect of

Acute Caffeine Injection on VTT

Following Daily Caffeine Treatment

11.

Dose Dependency of Chronic Dally

Caffeine Treatment on Subsequent Elevation of VTT

12 .

The Effect of Acute

vs. Chronic Caffeine Treatment on VTT

13.

Alteration of Isoproterenol Chronotropy

by Chronic Caffeine Pretreatment 
INTRODUCTION

Paul et al examined the relationship between coffee consumption and the incidence of coronary heart disease (CHD) in 1963. Since then, there has been a continuing controversy over the adverse effects of coffee intake on the incidence of $\mathrm{CHD}$ and its subsequent lethality. Problems inherent to clinical studies such as subject selection and uncontrolled variables seem to be responsible, at least in part, for the often conflicting results concerning this relationship. In the more than half dozen clinical studies found in the literature since the early 1960's, the risk factor of CHD assoclated with coffee consumption has ranged from no increased risk (Dawber, Kannel and Gordon, 1974) to a two fold increase in the risk of acute myocardial infarction (MI) seen in coffee drinkers (greater than six cups per day) as compared to non coffee drinkers (Jick et al.e 1973). The motivation for this laboratory study was to examine, in part, the overall question of the effect of coffee consumption on mortality due to sudden cardiac death. Strict controls used in laboratory studies were adhered to, with the intent of avolding some of the difflculties confounding the clinical studies.

It is known that the majorlty of persons dying from 
acute $M I$ do so suddenly prior to hospitalization (Kannel et al.e 1975). Furthermore, in studying this disease state, Lown and his co-workers (1969) have suggested that ventricular fibrillation (VF) is one of the primary causes of early sudden death associated with MI.

It has also been reported that sudden death due to arrhythmia (generally V.F. or cardiac arrest) is often seen even in those subjects with no overt pathological evidence of acute MI (Roberts and Buja, 1972). As a result it is not possible to predict which people are susceptible to this terminal event based solely on the status of their coronary circulation.

To understand the magnitude of this problem, it must be pointed out that estimates of the incidence of sudden death, without regards to etlology, ranges as high as 30 per cent of all deaths (Kannel et al.e 1975). Accordingly it seemed important to determine what effect caffeine, the often touted pharmacologically active agent in coffee, would have on the susceptibility of the heart to ventricular fibrillation.

Bellet and his co-workers studied caffeine's acute effect on cardiac vulnerability in the dog (Bellet et ale 1972). Their results demonstrated that an acute intravenous caffeine injection could significantly increase vulnerablilty by 30 per cent. Furthermore this caffelne induced increase in susceptibility to VF could 
be seen even in dogs whose vulnerability had al ready been increased by coronary artery ligation. Thus, the additive effects of acute $M I$ and acute caffeine administration would presumedly predispose the subject to spontaneous VF and sudden death.

For two reasons the relevance of the acute Intravenous effect of caffeine to the clinical situation seems less direct than has been inferred by Bellet and his co-workers. Firstly, caffeine consumption in man tends to occur on a dally basis for prolonged periods of time. Thus a chronic study would more closely approximate the clinical state. Secondly, caffeine is normally ingested orally, and not via the intravenous route. Based on these considerations the present investigation specifically set out to examine the effects of chronic oral caffeine administration on cardiac susceptibility to ventricular fibrillation. It was also of interest to examine the time course as well as the dose dependency of the caffeine effect. Finally this study examined whether caffeine's effect on cardiac vulnerablilty was related to any alteration of the cardlac catecholamine system. 
REVIEW OF IHE LITERATURE

To understand the significance of the experimental portion of this thesis, certain background information must be presented to orient the reader. The goal of this work is, firstly to determine whether or not caffeine alters cardiac vulnerability to ventricular fibrlllation, and secondly to study possible mechanisms of such an effect. Certain questions come to mind even before designing and performing these experiments. What is ventricular fibrillation and what is its practical significance? How has fibrillation been studied in the past? By what mechanisms does the heart become vulnerable to fibrillation? How can vulnerability be quantified? What factors are known to affect vulnerability? How might caffeine affect susceptibility to VF? The intent of this review is to present historical information which, in part, answers these questions. 
Fibrillation

Fibrillation has been defined as chaotic, asynchronous, fractionated activity of the heart (Moe, Abildskov and Han, 1964). Brooks et al. (1955) more graphically described the state as one in which groups of muscle fibers appear to "...contract independently of adjacent segments of the myocardium, imparting a vermicular movement to the chamber walls". Ventricular fibrillation (VF) was first described in the scientific literature in 1842 by Erichsen, but was not named fibrillation until 1874 when Vulplan first used the term "movement fibrillaire" to describe the arrhythmia in the dog.

Gross. observations of the heart in which VF is being initiated suggests that its inception is not necessarily an all-or-none state. The arrhythmia may initially involve large sections of the heart and then progress by a fractionation of activity into smaller and smaller independently contracting areas (Brooks et al. 1955). Certainly, once the heart sustains true fibrillation, no single pacemaker initiates coordinated excitation and contraction of the myocardium.

Garrey (1914) proposed the historic concept that VF was initiated by differences in excitability and conduction in different parts of the myocardium. The 
page

importance of this physiological asymmetry in promoting and maintaining this arphythmia has been relterated by numerous authors since first stated. In terms of specific electrophysiologic mechanisms involved in the initiation of fibrillation, there have been two basic theories since the time of Garrey. The first was Garrey's circus movement concept which postulates the irregular reentry of impulses. Alternatively. Engelman (1896) and later Rothberger and Winterberg (1914) proposed that ectopic focal stimulation arising from multiple foci, or a single focus initiated the fibrillation. Evidence supporting both of these mechanisms has accumulated over the past sixty years both from clinical and laboratory studies. Although the simple circus movement theory was attacked by Prinzmetal et al. (1.952), both theorles have prevailed to the present as evidenced by their review in monographs by Brooks et al. (1955) and Surawicz (1971).

Part of the reason for the continued acceptance of both of these constructs is the severe difficulty in identifying specific mechanisms causing fibrillation. Surawicz (1971) lists three reasons for this difficulty: (1) the impossibility of localizing the fiber or group of flbers in which the first wave of reentry begins: (2) the fact that in many types of experimentaliy induced fibrillation the onset seems to be due to a combination 
of factors: and (3) the limited number of studies in which all cardiac and extracardiac factors which might have contributed to the arrhythmia, were studied simultaneously. In any case, the present over-riding opinion held by cardiac investigators is that initiation of fibrillation is caused by a combination of these two factors.

The initiation and continuation of VF presents a clearly severe threat to the life of the intact animal. Cessation of effective pumping by the heart is seen in ventricular fibriliation as evidenced by a reduction in cardiac output to near zero. Consequently, perfusion pressure to the vital organs is severely decreased causing mortality.

Vulnerability to Ventricular Fibrillation

According to Surawicz (1971), there are three basic conditions which must be met for the initiation and maintenance of VF. They are: (1) the presence of some stimulus to initiate the disorder: (2) a disparity in the relation between conduction velocity and refractory period duration within different parts of the myocardium to foster reentry; and (3) the presence of a critical mass of myocardium to maintain the fractionated activity. 
Notably these criteria are in keeping with the original concepts that VF is inltiated by a combination of reentrant and ectoplc pacemaker activity.

\section{A. Excltable Stimulus}

Ventricular fibrillation is almost universally preceded by an acceleration of ventrlcular rate and/or a premature stimulus. The excltable stimulus can therefore be any event which alds in the initiation of such premature stimuli or in the acceleration of rate.

Increased automaticity, whether it be related to known pacemaker fibers or nonpacemaker tissue which aquires pacemaker activity, is one accepted mechanism of premature extrasystole genesis. The ability for normally initiated impulses to reenter in a repolarized portion of the ventricle is a second manner in which premature ventricular beats may develop.

Regardless of the mechanism by which these premature systoles occur, the moment at which they occur is crucial to their ability to initiate fibrillation. This was realized as early as 1920 by De Boer, who demonstrated that a single shock, when applied near the end of mechanical systole could initiate fibrillation in the frog's ventricle. Then, in 1934, King demonstrated a similar finding in the dog and went on to show that the shock had to fall during the $Q-T$ interval of the 
electrocardiographic cycle to initiate the arrhythmia. Much later, Smirk and Palmer (1960) reported that premature ventricular beats ( $R$ waves) which interrupted $T$ waves of patient's electrocardiograms could initiate VF. This $R$ - on - $T$ phenomena and its electrophysiologic basis in relation to the cardiac vulnerable period will be discussed later in this review. Suffice it to say for now that a ventricular extrasystole falling during this interval is capable of eliciting the arrhythmia.

The initiation of ventricular tachycardia and its conversion to fibrillation is obviously a second course of events leading to VF. The electrocardiographic differences between tachycardia, flutter and fibrillation indicate a progressive desynchronization of electrical depolarization and repolarization of the ventricles. Tachycardia exhibits distinct ventricular depolarization and repolarization in the vectorcardiogram, whereas flutter demonstrates the simultaneous occurance of these events - i.e. reflecting reentrant activity (Smirk et ale 1964). The conversion from flutter to VF indicates a change in the character of the reentrant activity; from that of a rhythmic reexcitation following a circumscribed pathway, to one of a total arrhythmlc activity following no prescribed path. 
page 10

\section{B. Factors Favoring Reentry}

Excitable stimuli, whether they be ventricular premature beats or ventricular tachycardia, will not initiate VF unless the ventricles are in a sufficiently nonhomogeneous state of electrical activity to sustain asynchronous reentry. Premature beats must fall during the vulnerable period to initiate the arrhythmia. That is not to say that all premature ventricular beats (PVB's) occuring during this period will cause fibrillation: however PVB's which occur outside the vulnerable period virtually never initiate VF. The basis for the existance of the vulnerable period is that during this portion of the cardiac cycle there is sufficlent inhomogeneity to allow the propogated extrasystole to undergo multiple reentry. The conversion of tachycardia to fibrillation is also due to increased inhomogenlety within the heart which, in turn, increases susceptlbllity to reentry.

The inhomogeniety alluded to in this discussion relates specifically to inhomogeniety of conduction velocity and/or refractory period duration in different portions of the heart. Those factors that increase that spatial disparity increase the likelihood of reentry and arrhythmogenesis.

A disparity of conduction velocities within the ventricles is seen in the normal heart. Purkinje fibers 
conduct at the very fast rate of 2 - 4 meters/second, whereas neighboring ventricular muscle conducts at a rate of only 0.5 to 1 meter/second. Factors that slow conduction velocity, particularly of the muscle fibers, are notorlous for fostering reentry. These include increased extracellular potassium concentration, stretch, electrical stimull, myocardial ischemia, etc.

Furthermore, premature beats tend to conduct more slowly than do normal beats, as a result of their slower rate of phase 0 depolarization. By abruptly slowing the conduction of the impulse once it reaches a depressed portion of the myocardium, it is possible for those cells bordering this zone to become reexcltable while the slowly traveling wavefront is still close enough to reexcite them.

Impliclt in the phenomena of reentry is that it can only occur in tissue that has regalned its excitabllity. Just as there are inherent differences in conduction velocitles in different parts of the normal heart, there are differences in the duration of the refractory perlods at various sltes (Han and Moe, 1964). Moe et al, (1955) have suggested that vulnerability to fibrillation, as a result of reentry, may have as its basis normal differences of action potential duration and the asynchrony of repolarization of nelghboring Purkinje fibers and muscle tissue. These differences in 
page 12

refractory period duration cause the conducted excltation wavefront to travel down the repolarlzed fibers prior to exclting those fibers with longer refractory periods.

This difference. In action potential duration between Purkinje fibers and nelghboring ventricular muscle fibers has been shown to be dependent on heart rate. Moore et al. (1965) reported that at rapld heart rates this difference is minimal, whereas at slower rates, action potential durations of the Purkinje fibers tend to lengthen dramatically relative to those of the muscle tissue.

Temporal dispersion of recovery of excltabllity has been directly measured by Han and Moe (1964) and again by Han et al. (1966a), Spear et ale (1973) and numerous other investigators. The work by Han et al. (1966a) again demonstrated that this dispersion of refractoriness was inversly related to heart rate. Agents known to increase the dispersion of refractoriness include sympathetic stimulation, ischemla, chloroform, toxic doses of ouabain (Han and Moe, 1964; Han et al.e 1964). Studies such as these, relating to temporal dispersion of recovery have taken on a major significance in that these investigators have correlated this dispersion of recovery with an increased susceptibility to fibrlllation (see Assessment of Vulnerability to Fibrlllation, Electrical Fibrlllation Threshold subsection). 
Premature beats increase susceptibility to VF by fostering reentry. Their slow conduction rate, their prolonged vulnerable period (Wegrla et al. 1941) and their abllity to increase the temporal dispersion of refractoriness (Han and Moe, 1964) are all

characteristics which promote reentry.

A proposed mechanism explaining the progressive desynchronization of ventricular tachycardia to VF is the multiple wavelet hypothesis developed by Moe and Abildskov (1959). In that proposal, premature reactivation increases the normal asynchrony in the recovery phase of excitabllity among adjacent fibers. In tachyarrhythmias the increased incidence of premature reactivation becomes so great as to set up adjacent areas of totally refractory tissue bordering potentially excltable fibers. These potentially excltable fibers border other refractory areas. This gross disparlty of electrical status in adjacent tissue allows for multiple reentry of a conducted beat to occur, which could then initiate the fibrillation.

In summary, all hearts have a certain degree of intrinsic inhomogenelty of conduction velocities and duration of refractoriness. Increasing that inhomogeneity fostors reentry, and correspondingly increases the susceptlbility to arrhythmogenesis. 
C. Critical Myocardial Mass

Garrey, In his pioneering studies on fibrlilation (1914), realized the importance of a critical myocardial mass in both the initiation and maintenance of the arrhythmia. In the 62 years since Garrey's report, numerous investigators have supported the finding that hearts of small animals are relatively immune to procedures inducing VF in larger species. Recently, Ederstrom (1976) reported that VF could not be initiated in ventricles with a surface area less than 10 square centimeters regardless of the age of the animal. Furthermore, persistant VF did not develop in ventricular tissue in which myocardial density was small (i.e. when the surface area/gm was greater than 3.50 square centimeters). Conversly when surface area/gm was 1.50 square centimeters or less, fatal VF could always be induced. These results suggest that not only is a critical mass required to initiate and sustain the arrhythmia, but also an adequate surface area and myocardial density is required for arrhythmogenesis.

Presumedly the necessity for the minimal density, surface area and mass to allow for fibrlllation is related to the heart's ability to sustain reentry. This supposition was supported by the findings of West and Lauda (1962). They demonstrated that the minimal weight of atrlal tissue in which sustained arrhythmia could be 
page 15

produced was equivalent to that theoretically required to maintain reentry.

Assessment of Vulnerability to Ventricular Fibrillation

Historically, to assess the vulnerability of the heart to VF it has been necessary to experimentally produce fibrillation. There are presently numerous techniques for inducing the arrhythmia. The use of each of them not only provides information as to the vulnerability of the heart to VF, but also sheds light on the pathophysiologic mechanisms involved in the genesis of the dysrhythmia. Depending upon the nature of the question under study, a given method of inttiating the arrhythmia wili perhaps be more appropriate than another method. As a result, the abundance of arrhythmogenic techniques has practical significance. In that the major interest of this research was to determine whether a given drug treatment altered the susceptibility of the heart to arrhythmia, the major criteria in choosing the method for measuring vulnerability was its quantitative nature. A second criteria in this cholce was the strength of the method as a model of in vivo arrhythmogenesis and sudden cardiac death. Faced with those goals, the following review of the major techniques 
utilized in assessing vulnerabllity was undertaken.

A. Non - Electrical Techniques

Szekeres and Papp discuss in their monograph (1.971) the various methods for inducing experimental arrhythmias. The non-electrical techniques can be outlined as follows:

1. Drugs or other chemical agents.

a) applied locally to the heart (i.e. aconitine, delphinine, mecholyl, veratrine or potassium salts)

b) administered through the blood stream

(i) as a single drug (large doses of antiarrhythmic agents, veratrine alkaloids, cardiac glycosides, $\mathrm{Ba} \mathrm{Cl} 2, \mathrm{Ca} \mathrm{Cl}_{2}$ )

(ii) a combination of various drugs - l.e. catecholamines plus sensitizing agents (cyclopropane, chloroform, halothane, benzene, etc.) or cholinergic agonists plus elther sensitizing agents or hormones

(iii) drug administrations combined with electrical stimulation

2. Mechanical or thermal disruption of normal cardiac electrophysiological activity.

a) coronary artery ligation and other mechanical techniques which cause ischemia 
b) local cooling or heating of the myocardium

3. Excitation of the central nervous system (CNS).

a) electrical stimulation of the CNS

b) intraventricular drug administration (e.g. acetylcholine, nicotine, caffeine, analeptics, tryptamine, $K C l$, and strophanthidin)

c) mechanical increase in intracranial pressure

As early as 1875 Boehm demonstrated that injection of barium chloride could produce cardiac arrhythmia. Later, Levy (1911) demonstrated that under light chloroform anesthesla, epinephrine could initiate VF.

It was not until the late 1930's, however, that fibrillatory agents were used to quantitatively assess the vulnerabllity of the heart to arrhythmia. Meek and his co-workers (1937) used test doses of epinephrine to assess vulnerability of dog heart to arrhythmia after treating the animals with several different volatile anesthetics. Shen and Simon (1938) seem to be the first investigators, using non-electrical techniques, to demonstrate a reduction in susceptiblilty to VF after treatment with an antiarrhythmic agent, namely procaine. Blumenthal and Tribe - Oppenhelmer (1939) suggested that a quantitative assessment of vulnerablility could be made by determining the amount of barlum chloride which was just sufficient to fibrillate the perfused cat's heart. 
page 18

Since the work of these early investigators, the use of non-electrical techniques have proved to be very useful as a means of studying both the pathophysiology of VF and the heart's susceptiblilty to the arrhythmia.

Mechanistically, the use of these non-electrical techniques relate to their capability to increase cardiac automaticity and/or to increase the ability of the heart to sustain reentry. Aconotine, first used by scherf (1947), increases automaticity when topically applied to the epicardium (Schmidt, 1960 and Matsuda et al.e 1959). Numerous authors have suggested that increased sodium conduction is responsible for this drug's increase in automaticity. Alternatively, locally applied cholinomimetics seem to initiate arrhythmia by increasing reentry (West and Lauda, 1962). Veratrine both increases spontaneous activity and, by means of slowing conduction rate, fosters reentry.

The usefullness of these non-electrical techniques relates to their ablilty to model naturally occuring, in vivo, arrhythmogenesis. Particularly relevent to this issue is the use of catecholamines in combination with volatile sensitizing agents to mimic arrhythmia development during gaseous anesthesla. Coronary artery ligation is useful in representing ischemic arrhythmogenesis. Furthermore, cardlac glycoside induced dysrhythmia directly relates to clinically 
observed arrhythmia seen in digitalis toxicity.

other non-electrical methods, however, do not offer acceptable models of in vivo arrhythmogenesis. For example, application of drugs directly to the epicardium is a totally non-physiologic phenomena. This disadvantage is overweighed, in some cases, by other advantages of the method; in particular the long duration of the elicited arrhythmia once it is initiated. Prolonged arrhythmias are particularly useful in studying the efficacy of antiarrhythmics in terminating on-going dysrhythmias.

The protocol related to the use of these techniques in assessing vulnerability obviously depends on the specific technique. For example, In using the technique of the direct application of a drug to, or mechanical alteration of the myocardial surface, the latency to arrhythmia would be an appropriate measurement. The use of intravenous drug administration, either as the only arrhythmogenic agent or in combination with other agents which facilitate dysrhythmia (e.g. volatile anesthetics), could be quantified by measuring the dose of the drug required to initiate the arrhythmia. Similarly, excitation of the CNS with drug administration could be measured according to the dose administered.

In discussing the actual use of any technique to assess cardiac vulnerability, its ease of development and 
page 20

application has practical importance. The intravenous injection of an arrhythmia-inducing agent to an anesthetized animal is a very straight forward procedure. Depending on the species being studled, the administration of a gaseous sensitizing agent may be either simple or somewhat involved. In general, though, the development of non-electrical techniques to assess cardiac Irritability present far less technological difficulties than does the development of electrical techniques.

\section{Disadvantages of non-electrical techniques,} however, often preclude their use in certain studies. If it is of interest to study the effect of a drug on the susceptiblility of the heart to an arrhythmia, then to assess that susceptibility with a combination of other drugs (e.g. epinephrine plus a volatile anesthetic) could complicate the results due to the possiblility of drug interactions. A second difficulty in using non-electrical techniques to assess drug effects on vulnerability is the inability of these techniques to continually follow the time course of the effect of the drug under study. This problem has particular relevence to this thesis in that numerous sympathetlc agonists as well as aminophylline have been shown (using electrical threshold techniques to measure vulnerabillty) to initially increase susceptiblilty to VF, but then within 
page 21

a matter of minutes to decrease that susceptibility (Han et al, 1964 and Moore and Spear, 1975). Finally, it is the nature of the non-electrical techniques that the arrhythmias they initiate are not readily reversible. Again, depending upon the question under investigation, this characteristic can elther be an advantage or di sadvantage.

B. Electrical Elbrillation Threshold Techniques

The electrical fibrillation threshold is the minimal current required to induce cardiac fibrillation (Szekeres and Papp, 1971). The concept of using the strength of an electrical stimulus as a measurement of susceptibility to VF was first introduced by Einbrodt (1859). For more than 75 years after Einbrodt's work, this technique found little or no use. Then Levine, in 1932. rekindled its use as a means of assessing vulnerability. Even prior to the time of Einbrodt, however, the use of electrical stimuli to induce fibriliation had been used; that is dating back to the work of Hoffa and Ludwig (1850).

During the Nineteenth Century and the early Twentieth Century, Investigators using electrical shock to initiate dyshythmia used prolonged shocks (lasting on the order of seconds). Presumedly these early workers used long-lasting shocks since shorter shocks, when 
delivered haphazardly during the cardiac cycle, were Incapable of consistently eliciting VF. De Boer (1920-1921) first demonstrated that a brief induction shock applied near the end of systole to the ventricle of the exsanguinated, hypodynamic, frog heart could initiate a condition similar to fibrillation. Ferris and co-workers (1936) then reported that delivering a 30 msec. shock during the relative refractory period, corresponding to the $T$ wave of the electrocardiogram, could elicit VF in the normally functioning dog heart. These findings suggested that there was a 'vulnerable period' of the cardiac cycle during which brief electrical shocks of relatively small strength could initiate ventricular fibrillation. It remalned for Carl Wiggers, Rene Wegria and their co-workers at the Western Reserve Medical School to further develop a sufficlent understanding of this vulnerable period so as to be able to propose a quantitative fibrillation threshold needed to assess vulnerablilty to VF in the intact dog heart.

In a serles of three papers in 1940 (Wiggers and Wegria, 1940a; Wegria and WIggers, 1940a; and Wegria and Wiggers, 1940b) these investigators demonstrated that brief (10-40 msec.) condensor or induction shocks could consistently initiate VF when delivered during the late portion (the last $60 \mathrm{msec}$.) of mechanical systole. This period, entitled the vulnerable period, corresponded with 
that of both De Boer (1920-1921) and Ferris et al. (1936). Fibriliation never developed when a shock of similar strength was delivered during any other portion of the cardiac cycle. Unlike the study of Ferris et al. (1936), the fibrillation initiated by Wiggers and Wegria (1940a) required electrical stimulation of only a localized region of the myocardium. Understandably, this finding had implications on the mechanism of electrically induced VF. Furthermore Wiggers and Wegria reported that rectangular, monophasic, electrical shocks that lasted 50 - 90 msec., were capable of eliciting VF only when delivered such that they were initiated or terminated during the vulnerable period. Longer D.C. shocks (100-140 msec.) could initiate fibrillation, assuming the shock was of sufficient energy, if initiated or terminated during the vulnerable period of a normally propogated beat or a premature contraction. Sixty cycle per second alternating current (A.C.) showed similar responses as did D.C. stimulation, except that prolonged A.C. stimulation (greater than 7 cycles) often initiated VF when the A.C. stimulus was initiated just after the vulnerable period (i.e. early diastole), whereas this was quite a rare occurance for D.C. shocks. The explanation of this particular finding lay in the fact that late A.C. cycles were apt to fall during the vulnerable period of previously developed premature contractions. Again. 
page 24

shocks initiated or terminated during the vulnerable period of any conducted beat could produce VF if of sufficient strength.

Following these preliminary studies, Wiggers and Wegria (1940b) proposed and tested their fibrillation threshold technique. The method consisted of measuring the minimal current strength of brlef (10-30 msec.) D.C. shocks which could initiate VF, when delivered, to any fixed region of the ventricular epicardium, during the vulnerable period. To maintain consistent thresholds in the same preparation, over time, it was determined necessary to defibrillate the heart within 30 seconds, maintain the animal's blood temperature within one to two degrees centigrade, use non-polarizable electrodes (e.g. platinum or silver-silver chloride), continually change the polarity of the stimulating current to further minimize polarization effects, and finally to allow at least 15 minutes between fibrillation and retesting. Using the technique, these investigators demonstrated an increase in the ventricular fibrillation threshold (VFT) in dogs treated with procaine $(8-10 \mathrm{mg} / \mathrm{kg}$ ) (Wiggers and Wegria, 1940b). Also, it was demonstrated by wiggers et al. (1940), that using this fibrillation threshold technique it was possible to show an increase in susceptibility to VF associated with myocardial ischemia. Since first being proposed as a method of 
page 25

quantifying cardiac susceptibility to arrhythmia, electrical threshold measurements have found wlde spread use: Presentiy there are three basic methods for VFT measurement using electrical stimulation. They are (1) the single shock method, (2) the alternating current method and (3) the trains-of-pulses method.

1) The single shock method

Historically the first acceptable quantitative method for VFT determination was the single shock method as proposed and refined by Wiggers and Wegria. In this method a single, monophasic, rectangular pulse of 2-30 msec. duration is applied to the heart during late systole. The pulse is delayed further and further into the $S-T$ segment untll passing the $T$ wave. It is then increased in amplitude and again the S-T segment is scanned until eventually fibrillation ensues.

The applied current initiates a premature beat when delivered at subfibrillatory amperage during the vulnerable period (Wegria and Wiggers, 1940a). When stimulating current is increased, temporal dispersion of recovery following the premature beat correspondingly increases (Spear et ale 1973). Colncident with this increasing inhomogeneity of repolarization of the ventricle, repetitive extrasystoles, ventricular tachyarrhythmia and finally VF are elicited. 
page 26

Indeed, a strong cause-and-effect relationship between increased temporal dispersion of refractoriness and increased vulnerablitty to arrhythmogenesis, as judged by the VFT, has been suggested by the work of Han et al. (1966a), Han et al, (1966b) and Spear est al. (1973). Ventricular fibrillation only occurs when the myocardium is grossly disparate in terms of recovery from excitation. The electrical stimulus can provide both an excitable stimulus (i.e. a premature beat) as well as a means of fostering reentry.

There are at least three characteristics of premature beats which contribute to the reentry process. The first is their relatively slow conduction velocity as compared to normal sinus beats. Secondly, premature beats tend to cause an increase in the normal temporal dispersion of "refractoriness (Han and Moe, 1964). Thlrdly, premature beats generally have longer vulnerable periods than do normal beats (Hegria et al, 1941). Surawicz et ale (1967) reported that those premature beats preceding multiple extrasystoles and VF have significantly shorter effective refractory period (ERP's) than do single premature beats. In turn, single premature beats have shorter ERP's than do normal beats. This shortened ERP is, most probably, one reason for the prolonged vulnerable period duration of premature beats. In summary, delivering a single electric pulse to 
the myocardium elicits a premature extrasystole. As the stimulation current increases, the electrical recovery from the premature response becomes more asynchronous. At some critical stage this asynchrony reaches the point where multiple reentry is made possible and VF ensues. Many of the early workers in this field (i.e. prior to the $1950^{\prime}$ s) did not pace the heart via a second stimulator. To be able to accurately place the stimulating pulse during the cardlac vulnerable period, many of these investlgators triggered their shock (with an appropriate delay circuit) from the electrocardiogram $R$ wave (e.g. Shumway et ale 1957). However, more recent investigators have often artificially controlled heart rate by supraventricular or ventricular pacing. Some have even severed autonomic innervation to the heart and crushed the SA node in an attempt to block spontaneous activity or reflex autonomic activation. Such pacing is necessary in the single pulse method using the dog, since In this preparation heart rate has been shown to be one determinant of the VFT (Han et ale 1966a).

In developing the single pulse technique, numerous authors have demonstrated that certain technical aspects of the method could affect the resulting threshold. The first of these determinants of VFT were those proposed by Wiggers and Wegria (1940b), and listed previously. Shumway et al. (1957) then reported that VFT was less 
page 28

when the stimulating electrodes were placed in the right ventricle as compared to similar measurements in the left ventricle. Van Tyn and Mac Lean (1961) examined three other factors which they thought could affect the fibrillation threshold: namely interelectrode distance, time interval between stimuli and anatomic location of the electrode placement. Their findings indicated that an interelectrode distance of $2-4 \mathrm{~mm}$ yielded significantly higher VFT values, as well as being more variable, than similar determinations with an interelectrode distance of 10-35 mm. Based on further study, these investigators determined that this difference was due to short circuiting of the stimulating current through localiy damaged tissue. It was also shown, by these investigators, that stimuli delivered 10 to 15 beats apart produced significantiy higher VFT's than stimuli placed three or four beats apart. Finally, Van Tyn and Mac Lean demonstrated that VFT was higher at the base of the ventricles than at the apex.

The single pulse technique mimics, to a certain extent, naturally occuring extrasystoles initiated by an ectopic pacemaker. The current delivered to the myocardium during threshold determination is greater than that just necessary to develop a propagated impulse i.e. the excitability threshold. However, the increased current density is required to increase the inhomogeneity 
page 29

of the ventricle to the point at which sustained arrhythmias can develop. In those clinical situations where the $R$ - on - $T$ phenomenon (that is a premature systole occuring during the $T$ wave of the previous beat) initlates arrhythmogenesis, the increased disparity in temporal recovery of excitabllity is generally caused either by increased sympathetic tone and/or ischemic coronary heart disease.

Other advantages of the single shock technique are. more generally, advantages of the entlre process of electrical fibrillation threshold testing. For example, one advantage of the electrical fibrillation threshold is the fact that the effect of the stimulation is readily reversible. Secondly, the procedure can be used to measure both increases and decreases in susceptibility to arrhythmogenesis. Thirdly, the method is capable of assessing vulnerability at relatively frequent time intervals. Fourthly, the quantitative nature of the threshold provides a means of developing dose-response phenomena when studying arrhythmic or antiarrhythmic agents. Finally, the technique is flexible enough to study the entire range of preparations from in situ, cardlac preparations, which are physlologic in nature and as a result often quite complex, to isolated portions of the myocardium, which provide a somewhat less physiologic model, but accordingly provide a simpler preparation. 
page 30

When comparing the single shock method to other electrical fibrillation threshold techniques, it is relativeiy time consuming and, as such, its use in studying rapldly changing processes is often precluded. The reason for the time consuming nature of the method is that the vulnerable perlod must be clearly defined so that the reported threshold is the minimal current value necessary to initlate arrhythmia. This problem can be extremely acute when the vulnerable period is very short. This difficulty is partlcularly relevent to this thesis since Lubbe and co-workers (1975) reported that isolated perfused rat heart had a mean vulnerable period of only 3 msec.

Another disadvantage of the single shock method is that the thresholds are somewhat higher than those measured using the trains-of-pulses method (Tamargo et ale 1975). High intensity shocks, especially when applied in each cycle, are capable of injuring cardiac tissue.

2) The alternating current method

Hoff and Nahum (1934) were the first to use alternating current $(60 \mathrm{~Hz})$ to assess vulnerability to VF. In their study 110 volt A.C. shocks lasting longer than 0.5 seconds and applied through bipolar limb leads consistently caused VF in the cat. Administration of a 
page 31

cholinerglc agonist (acetyl-beta-methyl chollne chloride $25 \mathrm{mg}$. S.C.) prevented the development of VF, but could not prevent atrlal fibrlllation. In addition. Hoff and Nahum reported that adrenalectomy combined with a bllateral removal of the stellate ganglia also protected the cat's heart from VF. Subcutaneous administration of adrenaline, however, again made the heart susceptible to fibrillation Induced by the 2-3 second train of A.C. pulses.

Later. Wegria and Wiggers (1940b) examined the methodology of A.C. Induced arrhythmogenesis. Their work utillized direct stimulation of a small portion of the dog's epicardlum with alternating current of much less voltage than that used by Hoff and Nahum. Trains of from 0.5 to 4 sine waves in duration $(8.3$ to $66.7 \mathrm{msec}$ ) acted like brlef D.C. shocks. That is, if applled during the vulnerable perlod and with sufficient strength, fibrillation ensued. Otherwise, that is if applled at some other portion of the cardiac cycle or at less than minimal strength, VF could not be elicited. The unitary nature of this oscillating stimulus was explained by the investigators as being due to the fact that all those cycles occuring after an effective pulse would occur during the refractory period of that effective pulse and, as a result have no further arrhythmogenic effect. Longer durations of A.C. stimulation (7-9 cycles), 
at currents below the threshold values of the shorter train lengths, were also shown to be incapable of causing the development of VF when begun at the inception of the vulnerable perlod. However, those longer trains were able to cause fibrillation when begun later in the cycle, vis. during early diastole. That reduction in the threshold current for such trains applied in early dlastole was said to be caused by a lower excitability threshold at that time. Accordingly, a premature extrasystole could develop at that time, and subsequent cycles could eventually fall during the vulnerable period of that propogated extrasystole. Such an occurance was thought to cause a reduced fibrillation threshold, an assumption supported by Han et al. (1966) but not proved until 1967 (Suglmoto et al.).

Sugimoto and co-workers (1967), in fact, restudied certain factors of the A.C. method in terms of their relationship to the measured threshold. A five second A.C. stimulation ylelded a threshold 30 times less than the threshold measured using a single, $10 \mathrm{msec}$. square wave pulse. Weak A.C. stimulation (i.e. 0.4 mamp.) had to be delivered for at least a perlod of 800-1000 msec. to initlate VF. Again, threshold decreased proportionally to the duration of the stimulation period. More specifically, as the stimulus duration increased, the number of extrasystoles increased, and threshold fell 
page 33

exponentially with that increase in the number of extrasystoles. By showing that this correlation of a reduced threshold with successive extrasystoles could be seen regardless of by whlch method of electrical stimulation the extrasystoles were generated and the vulnerability tested (i.e. trains of rectangular pulses or $60 \mathrm{~Hz}$ sinusoidal alternating current), it was concluded that the occurance of the extrasystoles, in and of themselves, reduced the threshold.

Use of the A.C. method has certain advantages over the single pulse method. Firstly the A.C. stimulus exactly mimics the electric shock delivered by $60 \mathrm{~Hz}$. wall current. Leakage of very weak currents from improperly grounded electrical equipment may initiate VF in patients (starmer et ales 1964). As a result, threshold testing using the A.C. method has definite practical significance.

Secondly, the threshold measured using the A.C. method is far less than that measured using the single pulse technique. This characteristic minimizes the possibility of damaging the myocardium with large currents.

There remains, however, practical difficulties in the use of sinusoldal alternating current to assess vulnerability. Primarily, because of the biphasic nature of the wave form, current measurement is technically 
page 34

difficult. Also it would seem to be necessary to Initiate the pulse train each time at the same point of the sinusoidal wave: otherwise the variable initial pulse would presumedly alter the threshold. This requirement again presents technical constraints.

3) The train of pulses method

The most recently developed method of electrical fibrillation threshold testing has been the train of pulses method. Han (1969) was the first to use this technique of applying a gated train of monophasic. rectangular pulses to the heart to assess vulnerability. In that first use, the train was initiated just after the $R$ wave of the cardiogram and was sustained just to the peak of the $T$ wave. Each pulse was $2-4 \mathrm{msec}$ in duration, and the pulses were delivered at a rate of 100 cycles per second. Current was progressively increased until fibrillation ensued; that current was then taken to be the fibrillation threshold.

One interesting result from this study was that the time interval between elicited extrasystoles became progressively shorter at increasing stimulation currents. As a result, it was possible to correlate the ventricular fibrillation threshold (VFT) with a minimal "critical" coupling interval. This finding had practical applicability in that it was used in that same study as a 
page 35

measure of vulnerability. Using trains of increasing duration, but constant current, susceptibility to VF was estimated by the duration of the train, the number of accelerating premature beats required to induce fibrlilation and the critical cycle length of the premature beat just preceding fibrillation (i.e. the interval from the previous beat to that extrasystole just preceding VF).

Because of its ease of application and, most notably the rapidity with which VFT can be measured, the train of pulses method has found widespread use in the past seven years (Moore and Spear, 1975). However, the underlying assumption that only a single pulse within the train initiates arrhythmia, and correspondingly that other pulses within the train have little or no effect on vulnerability does not seem valid. The study of Tamargo et al. (1975) reveals that the train of pulses method yields a significantly lower VFT than does the single pulse technique. Obviously then, the train represents more than just many stimuli; only one of which initiating VF.

More importantly, the threshold seen when using the train of pulses is highly dependent on the moment during the cycle at which the train is delivered. A train initiated very early in diastole and terminating at that point in the vulnerable period when fibrillation 
page 36

threshold is at a minimum (i.e. the nadir of the VFT curve), yields the same threshold as that found scanning the vulnerable period with a single pulse. However, a train initiated just at the nadir and progressing through the peak of the $T$ wave yields thresholds significantly higher than those measured using the single pulse (Verrier et al.e 1976). Weiss et al. (1973) found a similar increase in VFT when the train progressed past the vulnerable period nadir, and accordingly named this portion of the cycle the protective zone. Trains delivered very early in the refractive period, but ending prior to the nadir, also yield VFT's greater than the single pulse. Conversely, trains inltiated just prior to the nadir, but still progressing through the nadir and protective zone show thresholds significantly less than the single shock method; that is, as Tamargo et al. (1975) demonstrated. In conclusion, thresholds assessed using the train of pulses technique is highly dependent on train placement in the cycle relative to the nadir of the VFT curve.

Brady et all (1960) and later Vicenzi and West (1963) both demonstrated that trains of pulses were capable of causing the release of endogenous cardiac neurohormones, e.g. norepinephrine, and to a lesser extent, epinephrine. However, the Brady paper presents evidence suggesting that the single pulse is also capable 
of releasing cardiac catecholamines. As a result, this phenomena is probably seen with all modes of electrical stimulation of the heart. Therefore the secondary effect which the catecholamines may play on vulnerability would be seen, at least to some extent, with all modes of electrical fibrlilation threshold testing.

Although not a train of pulses method, the sequential $R$ on $T$ technique developed by Thompson and Lown (1972) and separately by Gamble and Cohn (1972) was based on successive decrease in threshold with successive extrasystoles. In the technique utilized by Lown's group, three monophasic rectangular pulses are delivered In close succession, each one being delivered just after the refractory period of the previous beat. This technique is thought to reduce the variables seen with the train of pulses technique, particularly in relation to the dependence of the threshold on train placement within the cycle.

Factors Known To Affect Vulnerablitty

As long ago as 1859 it was demonstrated in laboratory preparations that altering the vulnerability of the heart to fibrillation was possible (Einbrodt, 1859). More recently, it has become accepted in the 
clinic that certain agents. in particular antiarrhythmics, decrease vulnerablitity to VF whereas other agents and disease states may make the heart more susceptible to fibrillation.

A list of agents and interventions which have been shown to affect vulnerability would be quite large. Many have been referred to previously in this review. As a result, the present discussion will be limited to listing some pertinant agents and then going into detall only in those cases which have not been previously discussed and particularly warrant such discussion in terms of the focus of the present study.

A partial list of drugs reported to have reduced cardiac vulnerability to VF is presented in table 1. Most of these agents can be categorlzed into one of two broad groups. "The first group would consist of drugs which directly stabilize cardiac membranes and therefore reduce automaticity. This group includes the classical antiarrhythmic agents such as procaine amide. dihydroquinidine and 1 idocaine. The other group are agents which cause a reduction in sympathetic tone to the heart. Within this latter group are direct acting beta adrenergic blocking agents, e.g. propranolol and practolol, agents which are thought to indirectly reduce catecholamine release (reserpine, bretylium, perhaps edrophonium, methacholine and isoprenaline) and factors 


\section{IABLE $\perp$}

Drugs Which Reduce Vuinerability

to Ventricular Fibrillation

\section{$\underline{\text { DRUGS }}$}

\section{REFERENCE(S) *}

Acetylstrophanthidin (intact nervous system)

Ajmaline

Aminophyli ine (following brief elevation

$$
\text { in vulnerability) }
$$

Antazoline

Bretylium

Clonidine

Dibenamine

Dihydroquinidine

Diphenylhydantoin

Edrophonium

Epinephrine (following brief elevation in vulnerability)

1

2

3

2

$4,5,6$

7

8

2

2,9

10

$8,11,12$

Guanethidine

Hydroxyzine

I soprenal ine

Li docaine

Methachol ine

Morph ine

Norepinephrine (following brief elevation in vulnerability)

Novaca ine

Ouabain

Papaverine

Phenylephrine

Physostigmine

Practolol

Procaine

Proca inamide

Prone thalol

Propranolol

Quinidine

Reserpine
4

2

13

$2,6,14$

15

16

12

17

1

8,11

18

19

20

17

2,21

4

4,22

8,11

* References are listed by number in the appendix. 
page 40

which reduce sympathetic outflow as a result of CNS action (e.g. clonidine).

Table II provides a partial ilst of physiologic interventions which reduce vulnerablitity to ventricular arrhythmia. All cause a reduction in sympathetic tone to the heart. Arrhythmias associated with coronary occlusion seem to be related to a variety of sequelae to ischemia. Ischemic myocardium elicits neural and humoral responses which are pro arrhythmogenic. Sympathetic reflexes following coronary occlusion have been demonstrated by Malilani et al. (1969). Attenuation of cardiac vulnerabllity associated with ischemia is produced by beta adrenergic blocking agents. Humoral responses increase vulnerability during sudden reperfusion of the coronary circulation since it has been shown that beta blockade is Ineffective in reducing reperfusion associated arrhythmias (Lown et al.e 1977). Ischemic and Infarcted tissue also directly alters conduction velocity and causes disparity in refractory period duration within adjacent areas of myocardium. Such effects directly predispose the heart to arrhythmia (see Vulnerability To Ventricular Fibrillation). Development of collateral circulation prevents these effects by limiting the ischemic zone slze.

Other factors reported to increase vulnerability to VF are listed in Table III. One group of factors 


\title{
TABLE $\Perp$
}

\begin{abstract}
Physiologic Interventions Which Reduce Vulnerablilty to Ventricular Fibrlilation
\end{abstract}

\section{INTERVENTION}

Aortic Occlusion Induced Hypertension

Reduction of Psychological Stress

Right Stellate Ganglion Ablation

Collateral Coronary Artery Development

Prior to coronary artery occlusion

* References are listed by number in the appendix. 
page 42

increase sympathetic activity to the heart. A second group causes direct cardiac toxicity. A third group of factors increase vulnerability by unknown mechanisms.

Stress factors which predispose the heart to ventricular arrhythmia do so primarily by stimulating the sympathetic nervous system (reviewed by Raab, 1966). When stress is combined with other factors which increase sympathetic activity, e.g. myocardial ischemia, spontaneous ventricular arrhythmia is often evident. This extreme elevation in vulnerability to arrhythmia represents an additive effect of the two factors stimulating the sympathetic nervous system. A pertinant example of this additive effect is the demonstration that caffeine infusion further reduces VF threshold in dogs with coronary occlusions (Bellet et al.e 1972).

Caffeine - Its Relevent Pharmacology

A. Chemistry, Source and Pharmacokinetics

Caffelne, $1,3,7$ trimethyl xanthine, is one of a group of pharmacologically active xanthines including theophyline and theobromine. All the methylated xanthines directly stimulate the central nervous system. cardiac and skelatal muscie as well as producing diuresis 


\section{TABLE $\amalg I$}

Interventions Which Increase

Vulnerability to Ventricular Fibrillation

\section{INTERVENTIOII}

Metabolic acidosis

Anoxia

Myocardial ischemla

Abrupt coronary reperfusion

Premature venticular beats

\section{MECHANISMS * REFERENCE (s)**}

$A, C$

$A, B, C$

$A, B$

$A, C$

A

26

27

$28,29,30$

31

32
Digitalis (following propranolol or denervation)

Epinephrine or norepinephrine

(initially with infusion)

A

I soprenal ine

A

Aminophylline (during 20 minute infusion)

Caffelne (i.v.)

Ouabain (in toxic doses)

quinidine (in toxic doses)

Chloroform plus epinephrine

Aconitine

A

$A, B$

$A, B$

$A, B$

A

A

A

1

12

27

Hypokaelemia or hypercalcemia

Barlum chloride

Sympathetic nerve stimulation

Electrical stimulation of posterior hypothalamus

Caffeine injection to lateral ventricle

A

A

3

33

34

34

35

36

Psychological stress

B

$37,38,39$

40

12

B

40

B

41

B

42

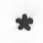

A. Direct acting cardiotoxins (including direct alteration of normal cardiac electrophysiology)

B. Increase sympathetic tone to the periphery

C. Unknown mechanism

** References are 1 isted by number in the appendix. 
page 44

and smooth muscle relaxation. Of the three major alkaloids in this class, caffeine tends to have the greatest effects on the brain and the least on the peripheral autonomic nervous system.

These methyl xanthines are found as natural products of various exotic plants. Caffeine is found in coffee, a decoction of coffee bean (Coffea arabica). Tea, an infusion of tea leaves (Thea sinensis) also contains caffeine as well as theophylline. Both caffeine and theobromine are obtained from cocoa, a product of Theobroma cocao seeds. Caffeine is also found in certain soft-drink sodas, partlcularly those in the cola famlly (from the nuts of the Cola acuminata tree) (Ritchle, $1975)$.

The amount of active alkaloid per cup of beverage has been given numerous values over the past Century, partiy as a result of differing measurement techniques and partly because of differences in definition, or lack thereof, of the term "cup". Recently Burg (1975) reported that a cup ( 5 to 5.5 oz or 148-163 $\mathrm{ml}$ ) of brewed, roasted and ground coffee contained from 64 to $124 \mathrm{mg}$ of caffeine. The average caffeine content of the eleven brands tested was $83 \mathrm{mg} / \mathrm{cup}$. A compllation of literature values from the past twenty five years provided an average value of $95 \mathrm{mg} /$ cup (see Burg, 1975). Burg stated that instant coffee contained an average of 
page 45

$59 \mathrm{mg} /$ cup while recent literature values suggested that there was $81 \mathrm{mg} /$ cup. Decaffeinated coffee contained just $3 \mathrm{mg} / \mathrm{cup}$. Tea has been analyzed as having anywhere from 28 (instant tea) to $42 \mathrm{mg} /$ cup (bagged tea), but again a survey of recent 1 iterature values suggested much higher values; $45 \mathrm{mg} /$ cup in instant tea and $65 \mathrm{mg} / \mathrm{cup}$ in leaf tea (data from Burg, 1975). These discrepencles in caffeine content seem to relate to the larger standard cup (i.e. $250 \mathrm{ml}$ ) used in many of the earller studies (Wolman, 1955). Theophylline has been found in only small quantities in black leaf tea $(<0.3 \mathrm{mg} / \mathrm{cup})$. Burg reported that tea has a theobromine content of $2.3 \mathrm{mg} /$ cup whereas cocoa contained an average of $252 \mathrm{mg} / \mathrm{cup}$ of this methylated xanthine.

Following oral administration in man, caffeine is rapidly and essentially completely absorbed from the gastrointestinal tract (Sant' Ambrogio et al.e 1964). Peak blood levels following oral administration of the caffeine alkalold were reached 30 minutes after ingestion. Caffelne sodium benzoate was absorbed more slowly from the gut. When taken by mouth, the peak caffeine level was seen 60 minutes following administration of the sodium benzoate salt. Injection (l.v.) of the same dose of caffeine produced the same peak plasma level and the same time course of metabolism as seen with oral administration of the salt (Axelrod and 
page 46

Reichenthal, 1953).

Caffeine is freely and rapidly distributed to various bodily tissues. The distribution of caffeine is directly related to the tissue water content - indicating unimpeded diffusion (Axel rod and Reichenthal, 1953). The initial decrease in plasma levels due to distribution of the drug is rapid. Half iffe in plasma is approximately 1.5 minutes (Sant' Ambrogio et ale 1964). Caffeine passes rapidly into the brain. Subcellular distribution indicates that caffeine is not accumulated in sealed cytoplasmic compartments. Compartmentation in the nucleus, however, is found to a small degree (Galli and Spagnuolo, 1975). The liver concentrates caffeine to a slight extent in that the ratio of tissue water caffeine to plasma water caffeine is 1.11 (Axelrod and Reichenthal, 1953). This concentration effect presumably indicates the site of biotransformation of the compound.

In man. 99 per cent of ingested caffeine is biotransformed prior to excretion. The major products of biotransformation are I-methyluric acid and 1-methylxanthine. Excretion of these products are in relatively equal amounts (RItchie, 1975). The half time of the biotransformation is approximately 3 to 3.5 hours (Axelrod and Reichenthal, 1953 and Sant'Ambroglo et al. 1964).

With the ingestion of eight cups of coffee $(80$ 
$\mathrm{mg} /$ cupl over a ten hour perlod, mean plasma caffeine levels were shown to rise from $0.45 \mathrm{mg} / 1$ to $4.1 \mathrm{mg} / 1$. This daily accumulation of caffelne was estimated to be equivalent to a therapeutic blood level of the drug (i.e. $180 \mathrm{mg}$ ), however there was no day to day accumulation of caffeine as demonstrated by its disappearance by the following morning (Axelrod and Reichenthal, 1953).

\section{B. Pharmacologic Activity}

\section{1) Central nervous system}

From biblical times it has been known that caffeine containing beverages, coffee in particular, stimulates the brain producing the feeling of wakefuliness and preventing fatigue. This cortical activation is accompanied by activation of other levels of the central nervous system (CNS), including midbrain, brainstem and spinal cord. Toxic manifestations of caffeine ingestion primarily include signs of CNS overstimulation including restlessness, excitation and insomnia with progression to delerium or convulsions at larger doses (Jokela and Vartiainen, 1959).

Beyond the behavioral effects there are other lines of evidence suggesting central nervous system actions of caffeine. The drug rapidly and easily passes into the brain. Nearly two thirds of that taken up by the CNS 
page 48

reaches the encephalon, while $23 \%$ is found in the cerebellum and $15 \%$ in the brain stem (Galli and Spagnuolo, 1975).

Peripherally administered caffeine is known to cause neurochemical alterations in the CNS. Following caffeine injection brain norepinephrine (NE) is thought to be released from neuronal storage sites since there is a short 1 ived increase in the NE turnover rate CBerkowitz et ale 1970; Waldeck, 1971 and Corrodi et al, 1972). Intraperitoneally injected caffeine $(25-100 \mathrm{mg} / \mathrm{kg})$ also caused a biphasic alteration in dopamine (DA) turnover rates (Waldeck, 1971 and Carrodl et al.. 1972). When injected 30 minutes prior to testing with caffeine ( 100 mg/kg i.p.). tritlated DA production from labeled tyrosine was doubled, indicating acceleration of DA turnover. However, when administered 2 hours prior to tritiated tyrosine, DA turnover was decreased (as measured 3 hours after the caffeine injection). Brain serotonin turnover rates are decreased with caffeine injection (Carrodi et ale 1972).

Further results from the Waldeck (1971) and Carrodi et al. (1972) studies suggest that the primary action of caffeine, at presynaptic sites, is to release both NE and DA. This conclusion is based on the following findings. Monoamine oxidase (MAO) inhibition increases the free cytoplasmic pool of catecholamines, which in turn reduces 
page 49

tyrosine hydroxylase activity by a feedback mechanism. As a result of decreased catecholamine synthesis, MAO inhibition is perceived to reduce turnover rates (Carlson et ale 1960 and Neff and Costa, 1966). Caffeine, however, reverses blockade of tyrosine hydroxylase related to MAO inhibition.

Caffeine induced release of NE and DA to the synapse would reduce the effect of MAO inhibition on catecholamine concentration in presynaptic cytosol. Released catecholamine may also be degraded by catechol-o-methyl transferase, found at postsynaptic sites. Furthermore, since caffeine significantiy accelerates the reduction of NE levels in mouse brain following dopamine-beta-hydroxylase inhibition, it must be assumed that caffeine directly releases catecholamine. The increased turnover rate following caffeine would therefore be evident regardless of any secondary inhibition of tyrosine hydroxylase.

There is also evidence to suggest that caffeine augments post synaptic dopaminergic and noradrenergic action. Waldeck (1973) demonstrated that concommitant caffeine injection augmented direct acting dopaminergic and noradrenergic agonists (ET 495 and clonidine. respectively) in their ability to reverse reserpine reduction in locomotor activity. This effect was still seen after tyrosine hydroxylase inhibition, thus further 
page 50

ruling out presynaptic effects. Since pimozide (a dopaminergic antagonist) blocks this caffeine related increase in locomotor activity, it is suggested that post synaptic dopaminergic augmentation is the cruclal factor related to this caffeine effect. Taking all these findings into consideration plus the fact that caffeine pretreatment reduces amphetamine - induced rotation (Carrodi et al. 1972), it seems that caffeine acts similarly to amphetamine, at least in terms of CNS effects. That is, caffeine causes release of catecholamines and stimulates postsynaptic catecholaminergic receptors.

\section{2) Peripheral nervous system}

Caffeine administration, whether it be via the oral route in man, the intraperitoneal route in the rat or the intravenous route in the dog, causes a release of catecholamines from neural and chromaffin tissue of the adrenal medulla. De schaepdryver (1959) first demonstrated an increased secretion of epinephrine (EPI) and NE from the adrenal glands following intravenous caffeine infusion in the dog. Peach (1972) and Poisner (1973) confirmed and extended these findings. Levi (1967) then reported that three cups of coffee Increased the urinary excretion of adrenaline by man. A similar investigation by Bellet and coworkers (1969) demonstrated 
page 51

an increase in total urinary catecholamines (45\%), norepinephrine $(32 \%)$ and epinephrine $(77 \%)$ following the consumption of two cups of instant coffee.

The effect of caffeine on cardiac catecholamine content and turnover has been studied by Berkowitz and Spector (1971). Caffeine injection (50 mg/kg, I.P.) caused no reduction in cardiac catecholamine content in the rat or guinea pig. Following blockade of tyrosine hydroxylase with alpha methyl paratyrosine (150 mg/kg), cardiac levels of NE and EPI were reduced. Caffeine administration following the alpha methyl paratyrosine injection, was associated with a significant increase in cardiac EPI content, but did not reverse the inhibitor induced reduction in NE levels. Since the increase in cardiac catecholamine content was not seen following adrenalectomy, the authors concluded that caffeine released adrenal epinephrine into the circulation. With depletion of cardiac NE stores, the circulating EPI would then be taken up by the heart.

Berkowitz and spector (1971) falled to demonstrate caffeine-induced release of the catecholamines from the heart. However, in the study by Westphall and Fieming (1968) reserpine pretreatment was shown to reduce aminophylline associated tachycardia. Furthermore, propranolol administration also reduced the chronotropic response of this methylxanthine. These results support 
activity.

Although caffeine is known to cause the release of catecholamines, it is now evident that this action is less significant than caffelne's direct effect on the heart. This conclusion is based on the fact that the xanthines have slightly different effects on the myocardium than do the catecholamines. Catecholamines accelerate tenson development in papiliary muscle, whereas methylxanthines demonstrate an increase in tension which develops slower than normal (Marcus et al. 1972). In contrast to catecholamine action caffeine prolongs action potential duration. Finally, caffeine increases contractile force in isolated guinea pig atria pretreated with reserpine (de Gubareff and sleator, 1965 ).

The supra-additive augmentation of beta agonist inotropism (RaIl and West, 1963) suggests that caffeine may exert part of its cardiovascular effect at some site other than the post synaptic catecholamine receptor. Possible molecular mechanisms of this activity will be presented in subsection $C$ of this discussion of caffeine's pharmacology.

In 5 normal patients, coffee consumption has been shown to produce cardiac effects which are very much in accord with the action of caffelne described above. Caffeine containing instant coffee (158 mg/6 oz cup) was 
page 54

consumed 20 minutes prlor to cardiac catheterization and hemodynamic assessment. A summary of the results demonstrated a $50 \%$ increase in left ventricular end diastolic pressure (from 4 to $6 \mathrm{~mm} \mathrm{Hg}$ ), an increase in left ventricular work (by $49 \%$ ), very slight sinus tachycardia, $43 \%$ increase in cardiac index and a $17 \%$ increase in cardiac oxygen consumption. No premature ventrlcular contractions were seen (Gould et al. 1973).

\section{4) Effects on ventricular vulnerability}

There are at least 5 experimental studies which have examined the effect of methylxanthines on vulnerability to fibrillation and subsequent death. A chronological review of those studies yield conflicting results. In most, the methylxanthines increase the susceptiblilty to arrhythmogenesis, however, in one the incidence of mortality with left circumflex coronary artery occlusion was reduced following methylxanthine administration (Le Roy et al.e 1942). Since these papers so directly relate to the present study, they will be discussed individually.

Dikshit (1934) demonstrated that small amounts of caffeine citrate $(15 \mathrm{mg})$ could produce cardiac arrhythmias when injected into the lateral cerebral ventricle of cats. The arrhythmia, which was seemingly ventricular in origin was associated with a marked rise 
page 55

in blood pressure. Furthermore, the injection of sodium barbitone $(25 \mathrm{mg})$ prevented the caffeine related arrhythmia.

Even prior to the Dikshit study it was demonstrated by Beattle et ale (1930) that intravenous caffeine administration $(35-45 \mathrm{mg} / \mathrm{kg})$ could produce extrasystoles in decebrate cats. This effect was thought to be due to a direct effect of caffeine on the heart, since section of the cardiac nerves and adrenalectomy did not prevent caffeine's arrhythmogenic action. Conversely, Dikshit's finding that $10-12 \mathrm{mg} / \mathrm{kg}$ caffeine would produce arrhythmla when injected intaventricularly suggests that the drug increases susceptibility to arrhythmia by acting within the CNS.

The effect of aminophylline was studied on the pathological course of left circumflex coronary artery ligation (Gold et ale 1937). Dally treatment with aminophylline $\left(25 \mathrm{mg} / \mathrm{kg}, 1 . \mathrm{m}_{\text {. }}\right.$ ) for perlods of three weeks following ligation caused no alteration in the slze of the subsequent infarct. Incidence of ventricular tachycardia was noticeably increased, however, in the aminophylline treated cats ( $47 \%$ vs. $9 \%$ ). Aminophylline was also shown to lower the irritabllity threshold in papillary muscle (Greiner and Garb, 1950).

The study by Le Roy et al. (1942) suggests that aminophylline reduces sudden death incidence in dogs 
page 56

following left circumflex coronary occlusion. The protective effect was increased with more frequent administrations of the drug (i.e. 200-300 mg/day, p.o. for several days prior to testing and 120-240 mg. i.m. before and after occlusion). The protective effect of aminophylline was also shown to be additive to the effects of atropine. The proposed mechanism of action was related to the ablilty of these agents to prevent coronary vasoconstriction and facilitate dilation of collateral coronary vessels.

Two recent studies have examined the effects of caffeine and aminophylline on VF thresholds in the dog. Aminophylline reduced threshold for almost all of the 20 minutes of infuson (Horowitz et al.e 1975). This reduction in VFT (30) was attenuated and reversed with continued aminophyline infusion. After the drug administration, threshold was elevated to $120 \%$ of control values. This biphasic alteration in threshold resembles the effect of intravenously administered epinephrine and norepinephrine (Han et al.e 1964). The similarity of effects may suggest a similar pharmacologic mechanism. Presumably aminophylline causes a release of adrenal and cardiac catecholamines and/or directly stimulates cardiac catecholamine receptors (see subsections 2 and 3 above). Bellet et al, (1972) demonstrated that caffeine sodium benzoate infusion ( $25 \mathrm{mg} / \mathrm{kg}$; equivalent to $12.5 \mathrm{mg} / \mathrm{kg}$ of 
page 57

caffeine base) reduced VFT by $15,32,29$ and 20 per cent, when tested 15, 30, 45 and 60 minutes following drug administration. There was no subsequent elevation in VFT over control values as was seen with aminophyline. The reduction in threshold was blocked by pretreatment with either propranolol $(0.2 \mathrm{mg} / \mathrm{kg})$ or practolol $(0.6 \mathrm{mg} / \mathrm{kg})$, again supporting the thesis of beta adrenergic mediation of the increase in ventricular vulnerablitity associated with xanthine infusion. Caffeine was also shown to reduce VFT (by $23 \%$ ) in dogs tested four days after coronary artery ligation - a procedure which, in itself, reduced threshold by 20 per cent.

C. Molecular Mechanisms of Action

Caffeine is known to alter three molecular pathways. These effects may mediate the pharmacologic activity of the drug as discussed above. the evidence to date, however, does not warrant ruling out other potential molecular mechanisms. Furthermore the effect of caffeine on each of these pathways is not necessarily mutually exclusive, i.e. altering one pathway may directly or indirectly alter a second effect of the drug. Caffeine inhibits cyclic nucleotide phosphodiesterase - the enzyme which metabolizes the physiologically active cyclic $3^{\prime} 5^{\prime}$ adenosine monophosphate (c AMP) (Butcher and sutherland, 1962). 
page 58

The elevation of intracellular C AMP levels following phosphodlesterase inhibition have been correlated with the positive inotropic effects of the methylxanthines (Kukovetz and Poch, 1975). Phosphodlesterase inhibition by the methylxanthines also potentlate the cardiac Inotropic effects of epinephrine, histamine and glucagon - all of which stimulate the synthetic enzyme, adenyl cyclase (Rall and West, 1963 and Mc Nelll and Muschek, 1972). Caffeine induced elevation in intracellular C AMP levels may be assoclated with an increase in susceptibility to arrhythmia according to the hypothesis of Podzuweit et al. (1976).

Caffeine is also known to increase transmembrane calcium flux and reduce sarcoplasmic reticulum uptake of calcium. The electrophysiological consequence of these effects are to prolong the plateau phase of the action potential. This end result is also produced by catecholamines, again suggesting similar activity of the two groups of drugs.

There are two significant differences between caffeine and catecholamine effects, however, which suggest different molecular mechanisms. Firstly, caffeine prolongs the active contractile state of myocardial muscle, whereas catecholamines shorten contraction by accelerating relaxation. Secondly, caffeine inhibits adenosine effects on the myocardium. 
The catecholamines do not produce this inhibition.

Caffeine inhibition of adenosine's effects is a third molecular mechanism by which it may act. Adenosine shortens action potential duration, reduces contractile force, slows heart rate and causes coronary vasodilation (Chiba et ale 1973 and Thorp and Cobbin, 1967). The effects of adenosine and other purines have been suggested to be related to stimulation of a 'purnergic receptor' (see review by Burnstock, 1972). Caffeine may be a purinergic receptor antagonist.

D. Caffeine Consumption, Tolerance and Therapeutic Use Consumption of caffeine in coffee and tea makes this compound one of the most widely used drugs in the world. Treating rats with forced consumption of high doses of caffeine for two weeks led to subsequent preferential consumption of the drug when the rats given the choice of drinking caffelne solution or water (Vitello and Woods, 1975). These facts suggest that caffeine has some positively reinforcing property which makes it habit forming.

Tolerance among coffee drinkers, develops to caffeine's diuretic, psychic and sleep disturbing actions. Caffelne significantly reduces heart rate when ingested by non coffee drinkers, but produces no consistent bradycardia in subjects who habitually consume 
page 60

caffenated beverages (Colton et ale 1968). Thus tolerance also develops to bradycardia with chronic coffee consumption.

The most important therapeutlc use of caffeine is related to its cortical stimulation. The dally cup of coffee is often used to allay fatigue and drowsiness. Occasionally, caffelne sodium benzoate may be injected $(0.5$ to $1 \mathrm{gm})$ in the treatment of poisoning by central nervous system depressants. Caffeine is more often used, generally in combination with an ergot alkaloid, in the treatment of migraine headache. The analgesic effects in such cases are thought to be due to a direct cerebral vasoconstrictor action of the combination. Ordinary headaches are often relleved by combinations of caffeine with an analgesic. Conversely, it has been reported that some habitual coffee drinkers exhiblt headaches following withdrawal of caffeine (RItchle, 1975).

other methyl xanthines, aminophylline in particular, are often effective in reducing the symptoms of bronchial asthma. Based on their rapid bronchodilating activity, they are widely used in many instances of bronchoconstriction. Aminophylline is also occasionally used as a direct cardiac stimulant in acute episodes of congestive heart fallure. Finally the xanthines cause diuresis, however they have received relatively limited use as diuretics since they are less effective than other agents. 
page 61

METHODS

Experimental Design and General Methods

\section{A. Baslc Design of Experiments}

Groups of 6 rats were injected, per os, with caffeine $(10 \mathrm{mg} / \mathrm{kg}, 30 \mathrm{mg} / \mathrm{kg}$ or $90 \mathrm{mg} / \mathrm{kg})$ or with water just prlor to ventricular tachycardia threshold (VTT) determination. In the acute study, naive animals were injected once with the appropriate solution immediately prior to urethan anestesia and ventricular vulnerability testing. Subacute studies examined the effect of daily oral administration of either caffeine solution or water for periods of 2 or 4 weeks prior to study. Finally. continuous treatment for 8 or 10 weeks prior to testing constituted subchronic study of caffeine's effect on VTT. In the subacute and subchronic studies, in all but one group, each animal was treated just prior to VTT testing with the same solution (either caffeine or water) he had previously been administered. This acute oral injection immediately preceding vulnerability testing was labelled the "challenge dose". Using this procedure, the alteration of the acute drug effect by previous chronic drug administration could be examined. However, in one group of rats treated for 10 weeks with $90 \mathrm{mg} / \mathrm{kg}$ 
page 62

caffelne, water was injected just prior to threshold testing, to differentiate the effect of continuous dally Injections from the acute drug effect.

In part II of the research, the effect of chronic caffeine treatment on the subsequent sensitivity of the rat heart to isoproterenol - induced tachycardia was tested. Rats were maintained on a dally regimen of either caffeine $(90 \mathrm{mg} / \mathrm{kg} / \mathrm{day})$ or water for 10 weeks. Studies of dose response curves of isoproterenol on heart rate elevation were then performed.

\section{B. Subiects, Animal Care and Drug Ireatment}

Albino, male, outbred rats weighing 150-175 gms were purchased from Charles River Breeding Labs and served as subjects in all experiments. Upon arrival at the Department of Pharmacology, the rats were either housed in colony cages (roughly twenty animals per cage) or separated into groups of 6 and housed in group cages. All animals were fed Agway Rat Chow and given tap water ad lib. All subjects were housed in the same room throughout the course of the experiments with the light automatically set to provide a 12 hour 1 ight, 12 hour dark cycle. The animal quarters were maintained at 72 degrees fahrenheit. The experiments were carrled out over the period of July, 1975 to March, 1976.

Two to three days after their arrival at the lab, 
those animals seperated into cages of 6 per cage were arbitrarily chosen to receive one of the various drug treatments as indicated above and were so labelled. All animals in a given cage therefore received the same treatment. The rats were taken, as a group of 6 , from their home cage and then individually weighed. While each rat was being weighed, his cagemates would remain in the small plastic rectangular cage layered with absorbant used to transport the animals. All such handling of the subjects occurred in the late afternoon and early evening (4 p.m. to 8 p.m.). That choice of time was made to parallel the normal waking period of the nocturnal rat. After several such days of being handled and weighed, the rats were ready to be initiated on drug therapy. Each afternoon, pure caffeine base (chemical grade purchased from Matheson, Coleman and Bell) was weighed on a Mettler analytical balance ( $\pm 1 \mathrm{mg})$ and then transferred to a 25 or $50 \mathrm{mg}$ volumetric flask. The volumetric flask was then filled approximately two thirds full with distilled water and the solution was heated to 40 degrees $C$, to allow the crystal to dissolve. More distilled water was added to the flask so that a final concentration of $45 \mathrm{mg} / \mathrm{ml}$ was attained. Necessary dilutions (to 5 and $15 \mathrm{mg} / \mathrm{ml}$ ) were subsequently made from this stock solution. All solutions were transferred to conical flasks and kept warm (30-35 degrees centigrade) 
page 64

to prevent precipitation of the base. A separate Erlenmyer flask was filled with distilled water, warmed and was used for injection of control animals.

Initiation of drug administrations to each group was scheduled such that the final VTT testing for all groups could be accomplished within an eight to ten week period. Schedules were also designed such that on a given day, 4 rats were completed with their daily treatments and were tested for ventricular vulnerabllity to tachyarrhythmia. Pairs of water treated and caffeine $(90 \mathrm{mg} / \mathrm{kg})$ treated rats or pairs of rats treated with 30 $\mathrm{mg} / \mathrm{kg}$ or $10 \mathrm{mg} / \mathrm{kg}$ caffeine were studied together on a single day.

Caffeine solution or water was injected, per os, in a volume of $2 \mathrm{ml} / \mathrm{kg}$ body weight. Curved stainless steel feeding tubes attached to 1 or $2.5 \mathrm{ml}$ plastic disposable syringes were used to inject the solutions. A separate syringe and feeding tube was used for each dose (i.e. water, 10,30 , or $90 \mathrm{mg} / \mathrm{kg}$ ).

Each afternoon, all rats receiving caffelne were injected prior to those groups recelving water injections. However, the order in which the caffeine treated groups (and their water treated counterparts) were injected was rotated such that no group would be injected either first or last on consecutive days. 
Ventricular Tachycardia Threshold Measurement

\section{A. Surgical Procedure}

On the day of threshold measurement, each rat was taken from his cage, weighed and injected (p.o.) either with the test solution which had previously been administered or with water (see Basic Design of Experiments). If 4 rats ( 2 caffeine and 2 water treated) were to be tested that day, the order of testing would be varied in one of the following ways: water-caffeine-water-caffeine, caffeine-water-caffeine-water, caffeine-water -water-caffeine or water-caffeine-caffeine-water. A similar sequence would be followed if 2 rats treated with $30 \mathrm{mg} / \mathrm{kg}$ caffeine and 2 rats treated with $10 \mathrm{mg} / \mathrm{kg}$ caffeine were tested on a single day.

Within ten minutes of oral injection the rat was anesthetized with urethan $(1300 \mathrm{mg} / \mathrm{kg}, 1 . p$. in a $20 \% \mathrm{w} / \mathrm{v}$ solution). A surface lead II electrocardiogram was recorded on a Grass Model 7 Polygraph and displayed on a Tektronix model $5103 \mathrm{~N}$ oscilloscope. Tracheotomy was then performed and positive pressure respiration instituted using a Narco $V-100 \mathrm{Kg}$ resplrator. Bllateral thoracotomy at the fourth and fifth intercostal space followed, with removal of the fourth rib bllaterally. The pericardium was incised, the heart exposed and the 
page 66

lungs retracted. Room temperature normal saline $(0.9 \% \mathrm{Na}$ C1) was dripped directly onto the epicardium at a rate of 40-60 drops/minute throughout the experiment.

Bipolar silver-silver chloride electrodes were then placed on the right atrial appendage to provide right atrial pacing. These electrodes were 0.025 inches in diameter and were plated prior to use by placing several pure silver electrodes in a $5 \% \mathrm{Na} \mathrm{Cl}$ solution and passing 3 volts of cathodal D.C. current through them. The anode was a single silver electrode also placed in the beaker of salt water (sidowski, 1966). Following the plating of these electrodes, they were soldered to electrically shielded teflon wires and coated with epoxylite for insulation. Just the tips of the electrodes were sanded so that electrode surface area could be estimated to be 0.0032 square centimeters. They were pressed against the myocardium so that there was no appreclable movement about the epicardial surface. However, the pressure was not enough to displace the entire heart. Interelectrode distance was approximately $2 \mathrm{~mm}$. Bipolar platinum wire electrodes (MS 303; Plastic Products Co.. Roanoke, Virginia) were similarly placed on the pight ventricular eplcardium approximately midway between the apex and the base of the ventricle. These electrodes, through which VTT test pulses were delivered, were placed on the epicardial surface with an interelectrode distance of 2-4 
page 67

$\mathrm{mm}$. Prior to use, the electrodes had 1-2 $\mathrm{mm}$ of insulation removed from there tips. Electrode diameter, without insulation (as reported by the manufacturer) was 0.010 inches. Stimulation surface area was estimated to be 0.0005 square centimeters.

\section{B Equipment Design}

Ventricular tachycardia threshold was measured by delivering a gated train of constant current monophasic rectangular impulses to the right ventricular epicardium during the vulnerable period of the cardiac cycle (modified from Han, 1969). Figure 1 provides a block diagram illustrating the electrical components for VTT testing. Right atrial pacing was instituted using a Grass $S 9$ stimulator. The RF isolated output from the pacing stimulator was connected to a custom built, semiautomatic shut off device, then to a constant voltage to constant current converter and current measuring junction box. The output from the junction box then paced the right atrium through the bipolar silver-silver chloride electrodes placed on the animal's pight atrium.

The test pulses of the train were generated by a Grass SD 9 stimulator which was ultimately triggered from the pacer 'synch out' jacks (Figure 2). Because of the design of the SD 9 'trig in' system, however, it was necessary to maintain a constant positive pulse of at 


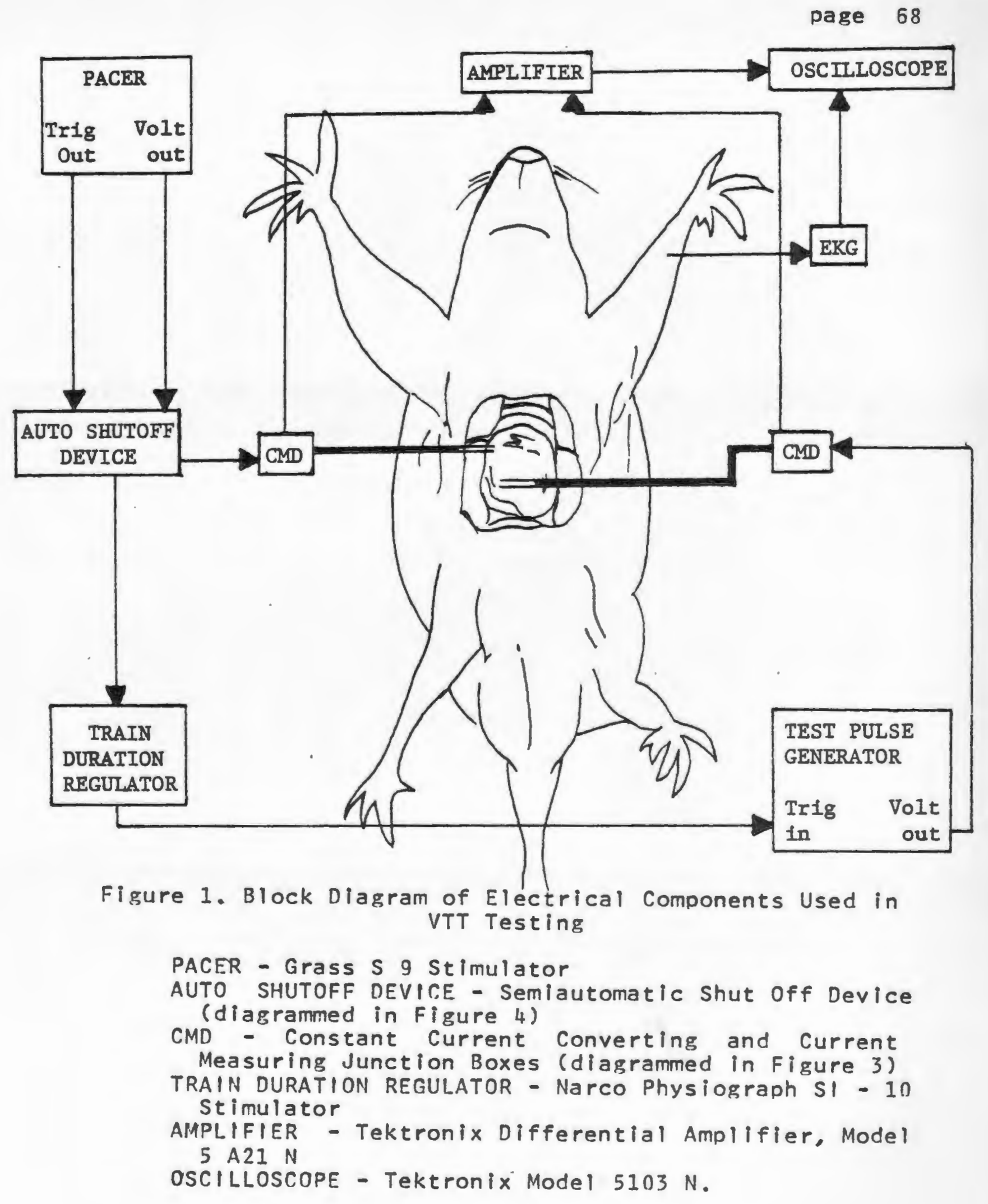


page 69

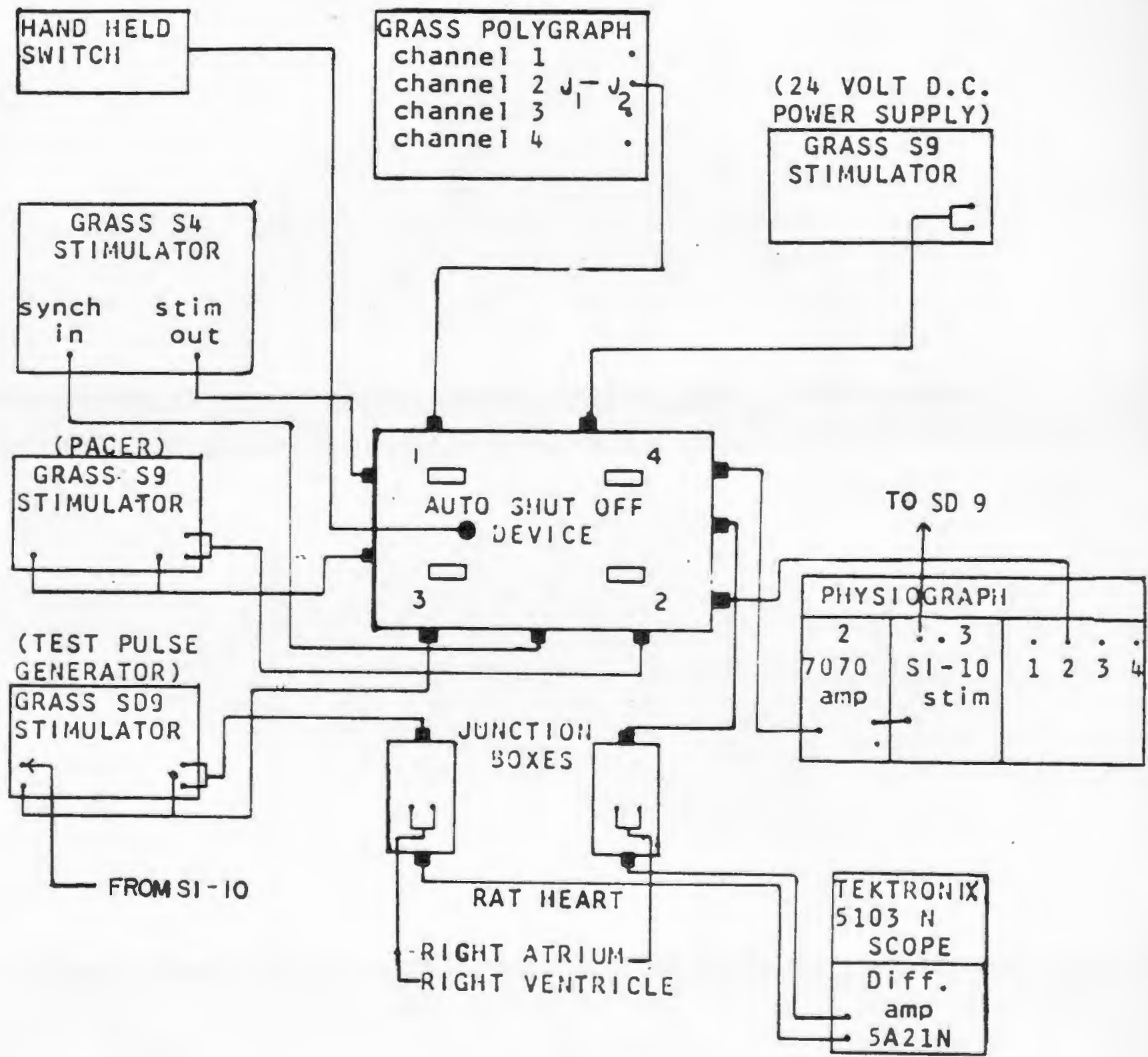

Figure 2. Wiring Diagram of Electrical Components Used in VTT Testing

The design is discussed in the text. 
page 70

least 10 volts at its 'mod in' input for as long as the train of pulses was to last. A Narco Physlograph Si - 10 stimulator was therefore used to generate such a positive monophasic pulse. Its duration was equal to the required train length. The $s 1$ - 10 stimulator was, in turn, triggered by the pacer synch out pulse, which was amplified by a Narco Physiograph Model 7070 amlpifier to meet the input requirements of the $S I$ - 10 stimulator.

With each pacing pulse, a train would be generated by the Grass SD 9 stimulator. However, its output to the rat's right ventrlcle was short circuited to ground by a normally closed hand-held switch (\#2)(see Flgure 3 ). As with the pacing pulse, the test train was converted from a constant voltage to a constant current source using a 1000 ohm series resistance (Shumway et al.e 1957). Current was measured by determining the voltage drop across a precision 10 ohm resistance (Figure 3). A Tektronix Differential Amplifier (Model 5 A21 N) quantified the voltage drop of both the pacing and test train output and displayed them on one beam of a Tektronix Dual Beam Storage Oscllloscope (Model $5103 \mathrm{~N}$ ). A simultaneously recorded electrocardiogram was displayed on the second trace of the oscilloscope.

Dellvering the test train to the animal's heart by depression the hand held switch (\#2 in Figure 3) was only performed just after activation of the semiautomatic 
Right Atrium

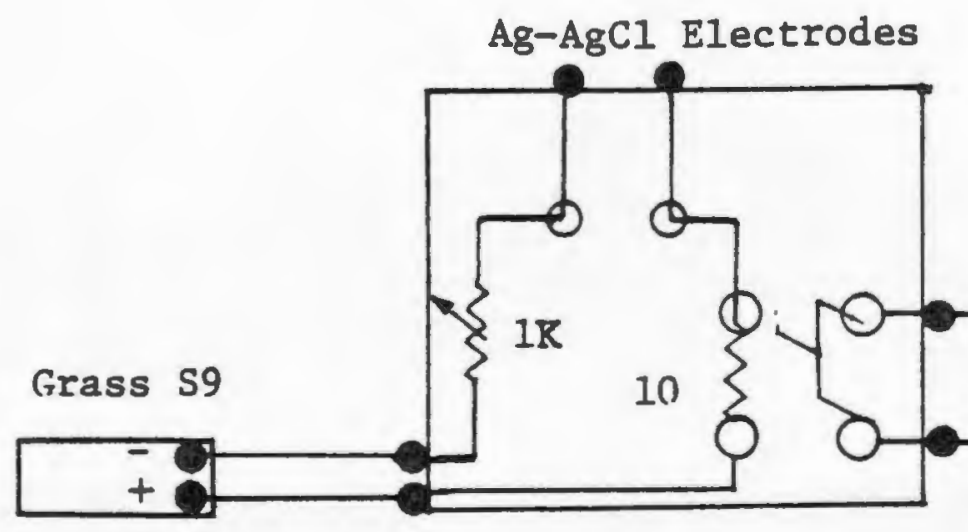

Tektronix Differential Amplifier Junction Box $5 \mathrm{~A} 21 \mathrm{~N}$

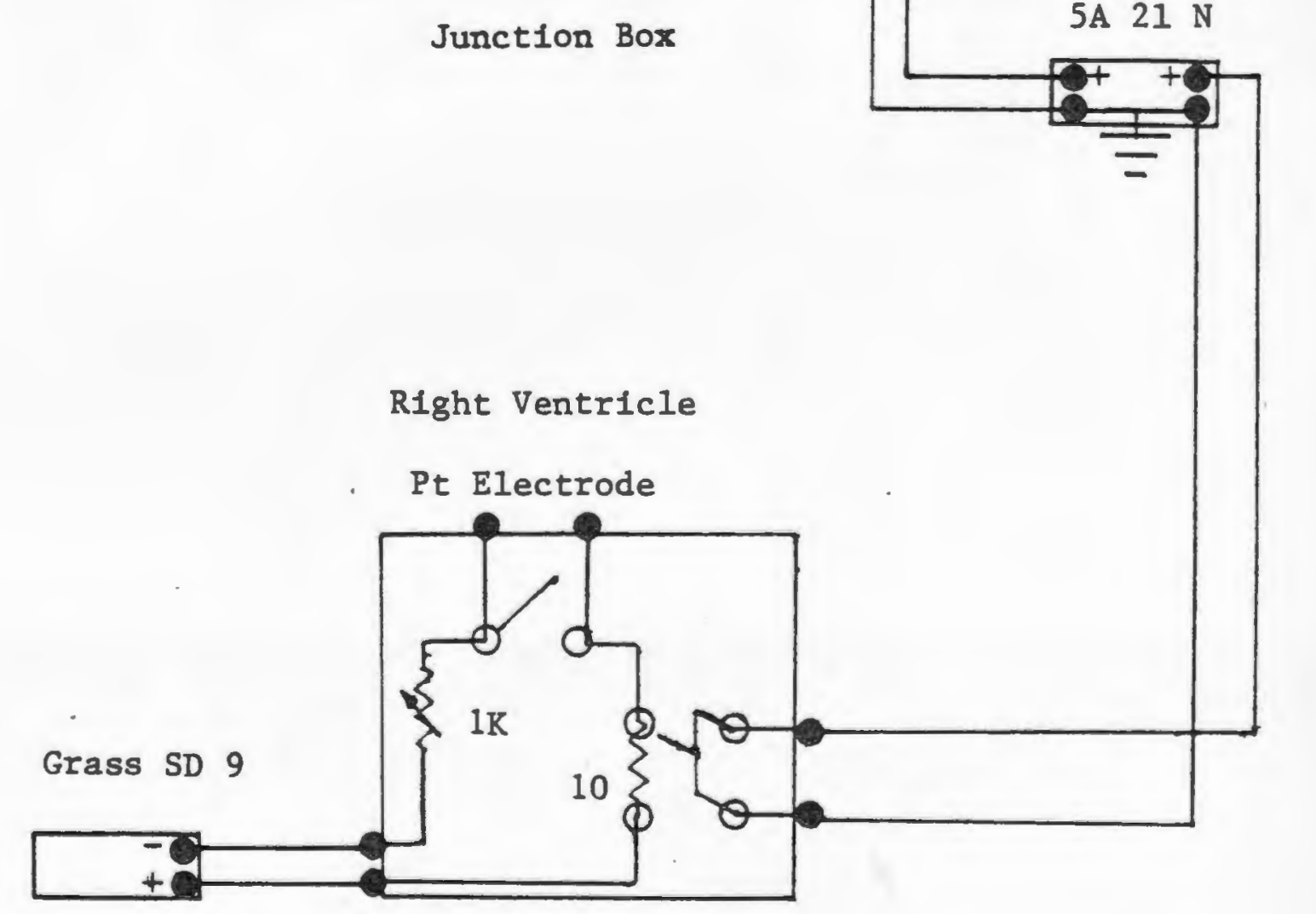

Junction Box

Flgure 3. Wiring Diagram of Constant Current Converting and Current Measuring Junction Boxes

Current is measured by determining voltage drop across a $10 \mathrm{ohm}$ resistor. Constant voltage source is converted to constant current source by passing current through a 1900 ohm resistance. Switch at right ventricular output is Hand Held Switch \#2. 
Channel Monftor **
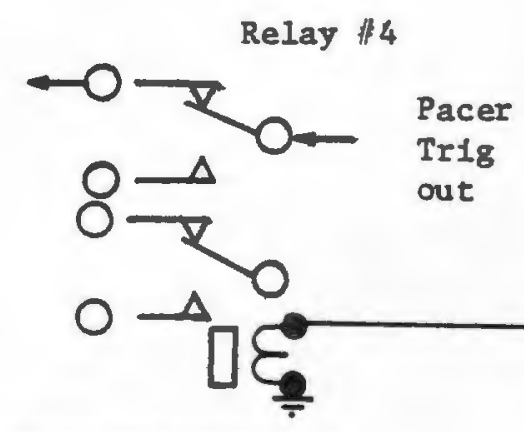

Tr1g

Relay \#2

out
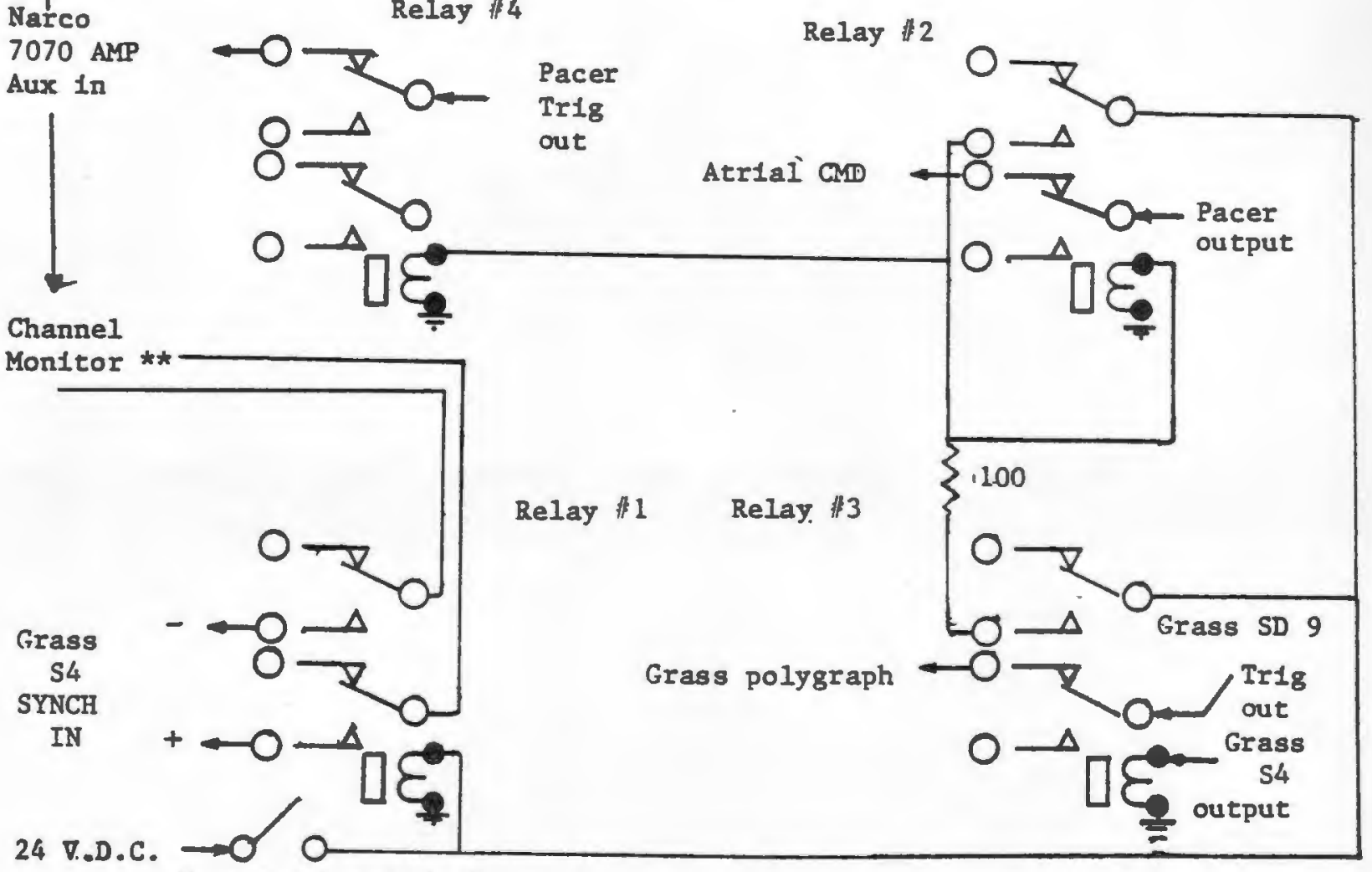

0

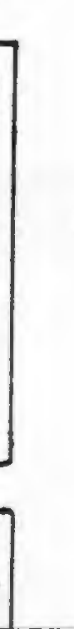

Hand held switch \#1

Figure 4. Wiring Diagram of Semiautomatlc Shut off Device

All relays are 24 volt D.C. electromechanical Type 100. Contacts are double pole, double throw. (Mi iwaukee Relays Inc.)

* Narco SI - 10 output to Grass SD 9 "Mod In". The Grass SD 9 stimulator generates trains of pulses only during that period when the 51 - 10 maintains a constant 40 volt pulse at the "Mod In" jack.

* 50 microsecond, 90 volt pulse from the Physiograph Channel Monitor. 
page 73

shut off device (Figures 1,2 and 4). Activation was initiated by depressing hand held switch \#1. The next pacing pulse and test train was then delivered to the rat. Simultaneously, the pacer trig out pulse operated an electromechanical relay ( \#3) via a fourth stimulator (Grass S4).

Output from the Grass 54 , "shut off" stimulator was delayed $140 \mathrm{msec}$ after triggering, to allow the pulse train to the ventricle to be completed. It then delivered a 1 second, 70 volt pulse to operate relay \#3. which, in turn, caused a 24 volt (D.C.) power supply to activate relay \#2. Operation of relay \#2 shorted future pacing pulses to ground. Release of hand-held switch \#I allowed pacing to be reinstituted. The semiautomatic shut-off device was thus designed to prevent any subsequent pacing pulses from possibly terminating tachyarrhythmia initiated by the test train.

\section{Stimulation Protocol}

Because the rat heart spontaneously beats at 230-240 beats per minute (BPM) under urethan anesthesia and open chest conditions, pacing was maintained at 250-300 BPM. The pacing pulse was a $3 \mathrm{msec,} \mathrm{monophasic}$ rectangular pulse usually 0.5 mamps in strength. Following 6-10 paced beats, the test train was delivered to the right ventricle by depressing hand held switches 
page 74

$\# 1$ and \#2 in rapid succession.

The pulse train consisted of 2 msec, monophasic rectangular pulses delivered at a frequency of $70 \mathrm{~Hz}$. It was delayed $10 \mathrm{msec}$ after the pacing pulse and continued for $90 \mathrm{msec}$. Thus, 6 pulses were delivered during the train. In relation to the electrocardiogram, the train was initiated just after the $P$ wave and terminated $j u s t$ prior to the $T$ wave (Figure 5). This placement assured that the train intersected the vulnerable period of the cardiac cycle, but did not encroach upon the protective zone found just after the vulnerable period.

Initially, the train was set at 2 mamp. If no sustained ventricular tachyarrhythmia developed at this current strength, pacing was relnstituted. Test current was increased by 2 mamp and following 6-10 paced beats, the train was again delivered to the ventricular epicardium. Sustained ventricular tachyarrhythmia was defined electrocardiographically, by a substantial reduction in mean arterlal blood pressure, and by visual identification of a fibrillatory quivering of the ventricles. The arrhythmia had to be sustained for two to three seconds (Figure 6). The ventricular tachycardia threshold was the minimal current which elicited sustained ventricular tachycardia. The VTT was measured between 40 and 60 minutes following oral injection of test solution and subsequent urethan injection. 

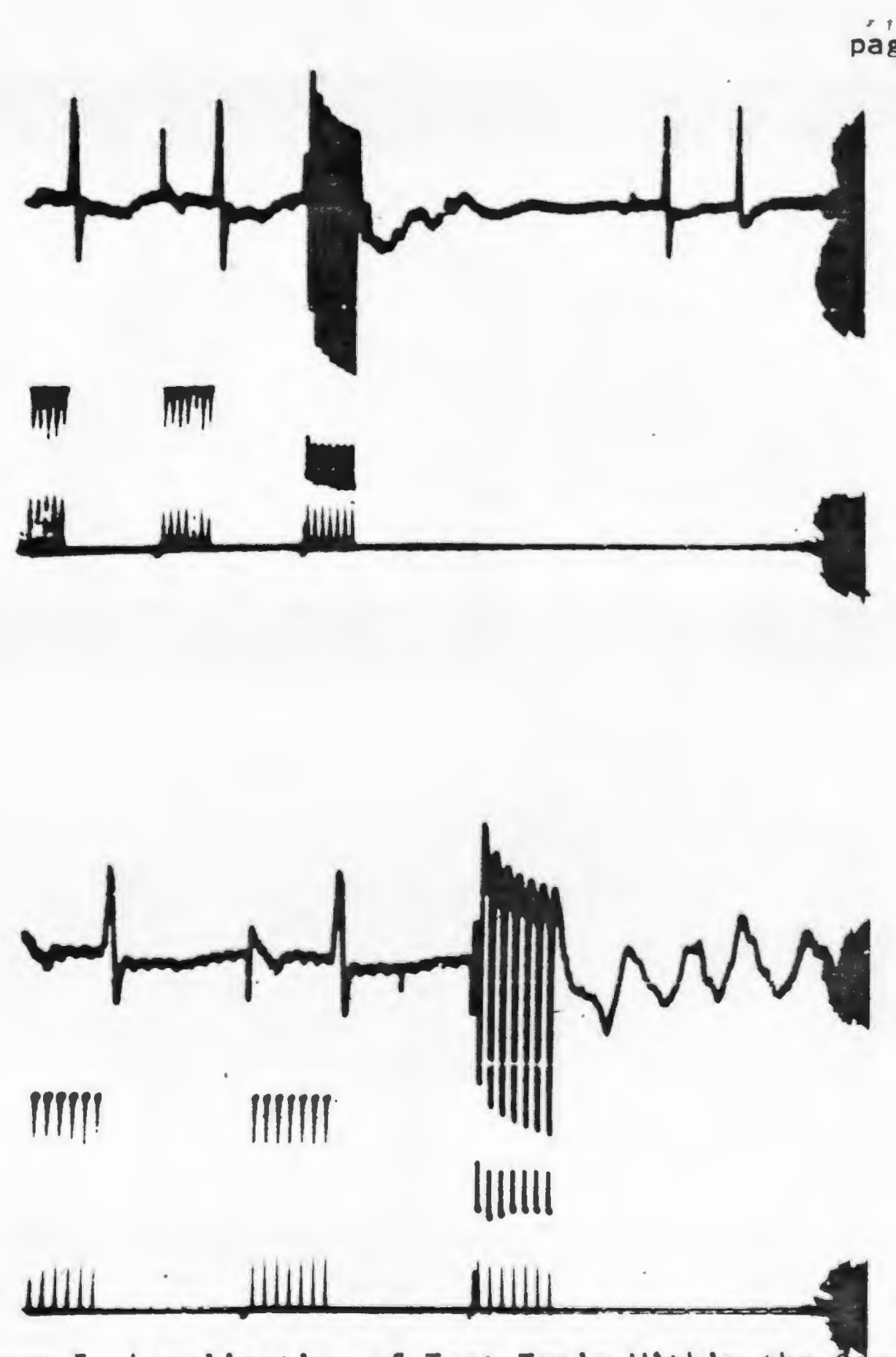

Figure 5. Localization of Test Train Within the Cardlac Cycle

The upper trace in each palr is the lead 11 electrocardiogram. The lower trace is a monitor of the output of the SD 9 Test Pulse Generator. The pulse is only delivered to the rat following the third paced beat. Train characteristics are described in the text. It is delayed $10 \mathrm{msec}$ after the pacing pulse and ends well before the $T$ wave. In the lower pair of traces current was increased to 12 mamps and VT was produced. Current in the top trace was 6 mamp. 


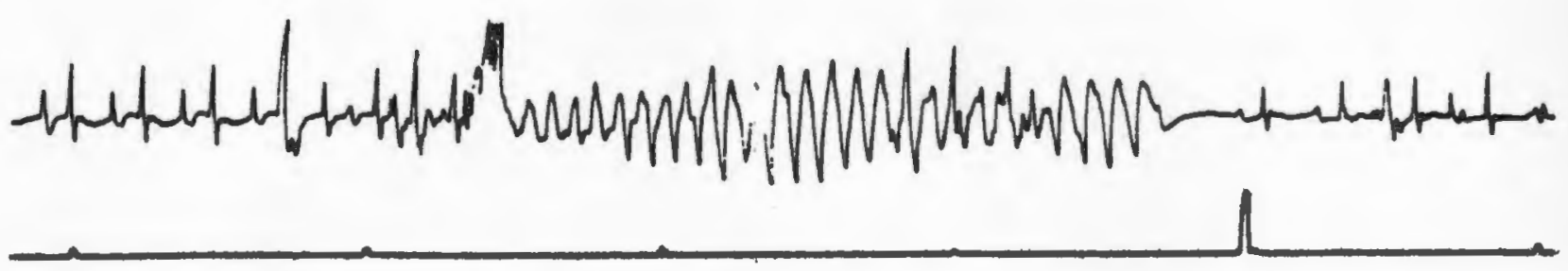

$100=$

1

Figure 6. Cardiographic and Hemodynamic Documentation of VT

The rhythmic ventricular complexes of rapld rate and the fall in mean arterlal blood pressure from 90 to $35 \mathrm{~mm} \mathrm{Hg}$ is characteristic of VT. The VT threshold was the minimum current which generated this cardlographic pattern, sustained for a minimum of 2 seconds.

The middle trace indicates time (in seconds). 
Effect of Chronic Caffeine Treatment on Cardlac Sensitivity to Isoproterenol

A group of chronic caffeine treated rats were tested with increasing doses of isoproterenol (Isuprel R; Winthrop Labs) to determine whether there was any difference in the chrontropic effect of this drug in caffeine treated rats as compared to water treated controls. Dally oral caffelne and water treatment was instituted in 2 seperate groups of rats for ten weeks as previously described. No acute drug treatment was given on the test day.

The rats were anesthetized with sodium pentobarbital $(50 \mathrm{mg} / \mathrm{kg}, \mathrm{i.p.})$. A surface lead 11 electrocardlogram was then recorded for measuring heart rate. Following cannulation of the external jugular vein for the injection of drug, a bilateral cervical vagotomy was performed. Isuprel $R$ was diluted with distilled water to concentrations of 2, 5, 20, 60 and 200 micrograms per milliliter. The vials containing the isoproterenol were air tight and covered with aluminum foll so that oxidation of the catechol would be minimized. The drug was infused at increasing doses with 10 minute intervals between each drug administration. Following intravenous injection of $0.5 \mathrm{ml} / \mathrm{kg}$ of isoproterenol, the catheter was flushed with $0.1 \mathrm{ml}$ of 
saline. Thus, the doses administered were $1,3,10,30$ and 100 micrograms per kllogram of body weight. Peak heart rate elevation was recorded following each dose of isoproterenol.

\section{Statistical Methods}

Unless otherwise noted, all data is presented as mean \pm standard error of the mean (SEM). Statistical difference between two groups of rats in a given experiment was analyzed by applying the Student's t test for unpaired data (two tailed). An 0livettl Programma 101 desk computer was used to compute means, SEM and $t$ values. Confidence limits (i.e. p values) were derived from standard tables.

To analyze the entire pool of threshold data, a two way analysis of variance (ANOVA) was performed. This analysis was capable of determining the significance of the overall drug effect on VTT, effect of the dally injection process and the interaction of the two. The least significant difference (LSD) was then calculated from the ANOVA so that multiple comparisons between groups could be made.

Linear regression analysis was also performed on dose-response data and on time-response data to determine 
page 79

trends from different experiments. Regression analyses were performed either by the 0livetti Programma or the University of Rhode Island IBM computer. Anova was also performed by the STATPACK program of the IBM computer.

Justification of Methods

A. VTI as an Estimate of Vulnerability

As discussed in the Literature Review (Assessment of Vulnerability to Ventricular Fibrillation), the ventricular fibrillation threshold provides an accurate, reproducibie method for assessing susceptibility to dysrhythmia. Its use dates back to 1859, and there have been a plethora of studies since then discussing variables which might alter threshold. Furthermore, in the study by Bellet et al. (1972) where the effect of caffeine on vulnerability to arrhythmia was examined, VFT thresholds were measured. To facilitate direct comparisons, threshold measurements were made in this study. Rat heart does not fibrillate, according to electrocardiographic definition. Thus, VT threshold was measured as an index of susceptibility to fibrillation in larger hearts. Estimation of vulnerability to VF by delivering subfibrillatory currents have also been proposed by Lown and Verrier (1975). With increasing 
current intensity to the dog's ventricle, single repetitive extrasystoles, multiple extrasystoles, VT and finally VF were produced.

The train of pulses method of measuring VTT was particularly suited to this research, as time required for testing is relatively short. This advantage was considered crucial to the study of any rapidly changing alteration in threshold. To prevent the train from encroaching the protective zone of the cardiac cycle, it was necessary to pace the heart at supranormal rates.

To prevent the progressive increase in threshold with time, non-polarizable electrodes ( $P$ t and $A g-A g C l$ ) were used. Fibrillation was prevented (it is not found in rat) and test currents were delivered no more frequently than once each 6-10 beats. Furthermore. VTT was measured from right ventricular sites rather than from the left ventricle. The right ventricle tends to be more vulnerable to electrically induced arrhythmia than is the left (Shumway et al.e 1957). Thus, smaller stimulating currents could be utilized. The use of the train rather than the single pulse method also results in smaller thresholds and therefore reduces damage to the myocardium.

Urethan was chosen as the anesthetic for use in these VTT studies, because it has minimal effects on autonomic nervous system activity or the cardiovascular 
page 81

system. Barbiturate anesthesia tends to increase vagal activity. Since vagal activation reduces vulnerablilty in the presence of increased sympathetic tone, this anesthetic was not used for VTT determinations. Furthermore, barbitone has been shown to reverse and prevent cardiac arrhythmia associated with intracerebroventricular caffeine injection (Dikshit, $1934)$.

B. Use of the Rat as the Experimental Species

Rats served as experimental subjects in these experiments. The laboratory rat has certain traits which makes it attractive for studies such as this. They spontaneously revert to normal sinus rhythm following VT. This characteristic obviates the necessity of high energy defibrillation." Rats are also inexpensive to purchase and maintain. Thus, large numbers of animals can be studied. Genetic variance between laboratory bred rats of the same strain are minimal. The rat is also easily injected per os. All of these characteristics makes the rat an attractive laboratory animal for this investigation, when compared with the dog. Although-dogs have been classically used to study vulnerablilty to fibrillation, practical considerations 1 imited their use here.

Ventricular fibrillation thresholds and vulnerable 
page 82

period measurements have been made in isolated perfused rat heart (Lubbe et al.e 1975). Results from that study support the use of the rat heart as a convenient and reproducible test system for estimating VFT and vulnerable perlod characteristics.

\section{Caffeine Administration}

The intent of this study was to examine the effects of caffeine on cardiac vulnerability to VF. The doses of caffeine were chosen to grossly mimic doses consumed by humans. Because of differences in pharmokinetics and pharmacologic dose-response effects, the dose normally consumed by humans was increased by a factor of ten (on a $\mathrm{mg} / \mathrm{kg}$ basis) for injection into the rats. This

conversion factor is a common value comparing the toxic effects of drugs in rat and in man. An estimated lethal dose of caffeine in man is $10 \mathrm{gm} \mathrm{(RItchie,} \mathrm{1975).}$ whereas, the LD of oral caffeine administration has been reported to be $330 \mathrm{mg} / \mathrm{kg}$ (Bond et al 1973 ). Assuming a human weight of $70 \mathrm{~kg}$, the lethal dose of 10 gm was equivalent to $143 \mathrm{mg} / \mathrm{kg}$. However, this human lethal dose is most certainly not an LD, nor for that matter is it an LD. It is simply a dose reported from a case study (unreferenced by Ritchie) that was lethal following oral ingestion. As a result, it is difficult to compare the lethal dose in human with that in the rat. 
The range of doses chosen to be administered to the rats on a chronic basis was large enough such that any possible effect which caffeine might have would he expected to be evident. Dose-response data from single injections of caffeine supported the choice of 10,30 and $90 \mathrm{mg} / \mathrm{kg}$. The lowest dose caused no appreciable effect, whereas the two higher doses produce similar effects when given acutely. Treatment for ten weeks was chosen as the maximal length of study. Shorter periods of study were also undertaken, but no longer studies were carried out. Again, it was arbitratily decided that any effect of long term caffeine treatment would at least start to become evident after 10 weeks of injections.

Challenge treatments, i.e. oral drug

administrations immediately prior to VTT testing, were performed in all groups. The rationale for acute drug administration in the long term treatment groups was to allow for direct comparison of the acute drug effect between two different treatments; i.e. naive and chronically treated animals.

D. Isoproterenol Dose Response Curves

Isoproterenol increases heart rate by stimulation of beta-adrenergic receptors. Direct activation of cardiac beta receptors causes tachycardia. In addition. the hypotensive action of the drug will elicit a 
page 84

baroreceptor reflex mediated Increase in sympathetic tone. to the heart.

The sensitivity of the cardiac beta receptors to adrenergic stimulation was examined in rats treated chronically with caffeine. Caffeine has been shown to activate the the beta adrenergic receptor (see Literature Review). Specifically, the action of caffelne in reducing the VFT in dogs (Bellet et al.. 1972) was shown to be blocked by propranolol and practolol. As a result, any effect of chronic caffeine treatment on subsequent VTT would logically be thought to be medlated by this catecholaminergic system. Admittedly other, more complex mechanisms can be envisioned. Examination of the cardiac beta receptor sensitivity was the most reasonable first step in elucidating a mechanism of action.

\section{E. Statistical Analysis}

Because of the combination of varlables being examined ( $1 . e$. drug treatment at different doses and oral injection for different times) the two way analysis of variance was used to quantitate the varlance of the VTT data and the significance of the effects of these variables on VTT. Within a particular experiment, however, the student's $t$ test was more sensitive to changes in threshold and was therefore applied. The Student's $t$ test is designed to test the ability of a 
page 85

single treatment to alter the parameter under study. Within a given experiment (i.e. acute caffeine vs, acute water treatment) all animals were housed together, treated over the same time period and tested on successive days. Thus, except for the speciflc treatment, all variables which might cause a difference in thresholds between the two groups were minimized. The Student's $t$ test was therefore considered to more accurately reflect differences between two groups within a given experiment than the analysis of variance. 


\section{RESULTS}

Introductory Remarks

Twenty-three groups ( 6 rats/group) were tested for vulnerability to ventricular tachyarrhythmia. Four of those groups were given only an acute single oral injection (either water or caffeine; 10,30 or $90 \mathrm{mg} / \mathrm{kg}$ ) prior to threshold measurement. In nineteen groups, daily oral administration of one of these solutions was administered prior to the test day, at which time the same solution was injected $(p .0$.$) just prior to VTT$ testing. In one group caffeine was administered for 10 weeks $(90 \mathrm{mg} / \mathrm{kg} /$ day $)$, but the rats were challenged with distilled water immediately before vulnerabllity testing. Finally, one group was given no treatment prior to anesthesia and VTT determination.

of the 138 rats initially included in the VTT study, no data was recorded from eight. Two chronically treated rats died immediately following an oral administration of caffeine. Death followed violent major motor seizures. Three other rats died from anesthesia at the time of VTT testing, and two animals who had severe respiratory infection were discarded from the study. those animals who were not included in the study were 
from different treatment groups, with the exception of two rats from the 10 week, $30 \mathrm{mg} / \mathrm{kg}$ caffeine treated group. Based on the mean and standard error of the mean, calculated VTT's for the missing animals were generated so that the mean and standard error of the group would be minimally affected.

Initial experiments on VTT measurement suggested that VTT increased with time following urethan anesthesia (Figure 7). Alternatively this progressive elevation in threshold could have been the result of repetitive electrical discharges to the heart during testing. This possible explanation was investigated by examining the correlation between initial determination of VTT and time following anesthesia. The data presented in Figure 8 shows that there was no significant correlation between these parameters. Since these results suggest that threshold did not increase with time following anesthesia, no detailed analysis was subsequently performed of the time at which threshold was measured. However, in light of the progressive rise in VTT, in the remainder of the study the VTT was taken to be the first threshold value recorded.

A two-way analysis of variance (caffeine dose and treatment duration versus VTT) demonstrated that both of these parameters altered threshold $(p<0.05)$. Based on the knowledge that each factor was responsible for a 


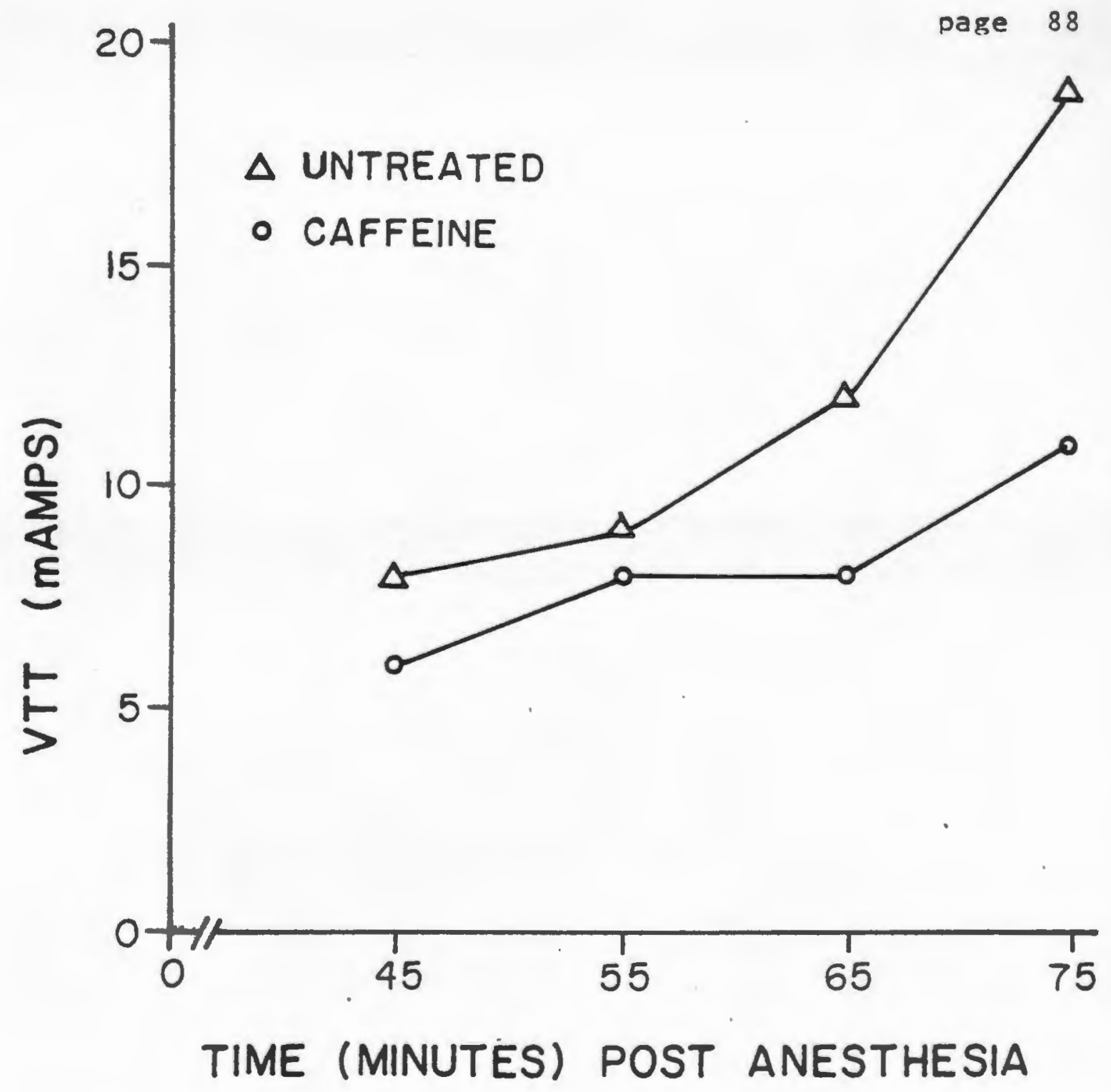

Figure 7. Progressive Elevation in VTT Following
Anesthesla

VTT was measured at 5 minute intervals. Both the caffeine treated and untreated rat demonstrated a progressive elevation in VTT with repeated testing. 
change in VTT, and the realization that the effect of acute caffeine administration was totally different from the long term effect, the results were analyzed in two sections. In the first, alterations in VTT by acute drug administration are presented. In the second, chronic drug effects are examined.

Effect of Acute Caffeine Treatment

single, acute, oral injections of either water or caffeine reduced VTT from that measured in untreated control animals (Figure 9). Hater injection caused a $35 \%$ reduction in threshold ( $p<0.1)$, but caffeine administration produced an even greater effect than that seen with injection of the vehicle. The reduction in VTT by caffeine injection did not reach statistical significance $(p>0.05)$ when administered at $10 \mathrm{mg} / \mathrm{kg}$. With larger doses $(30$ and $90 \mathrm{mg} / \mathrm{kg})$ thresholds were significantly reduced. However, increasing the dose from 30 to $90 \mathrm{mg} / \mathrm{kg}$ caused no further reduction in VTT. The maximal change in threshold with acute caffeine treatment was a $52 \%$ decrement.

To differentiate the caffeine effect on VTT from that of the oral injection process, caffeine treated groups were compared with water treated controls. Mean 


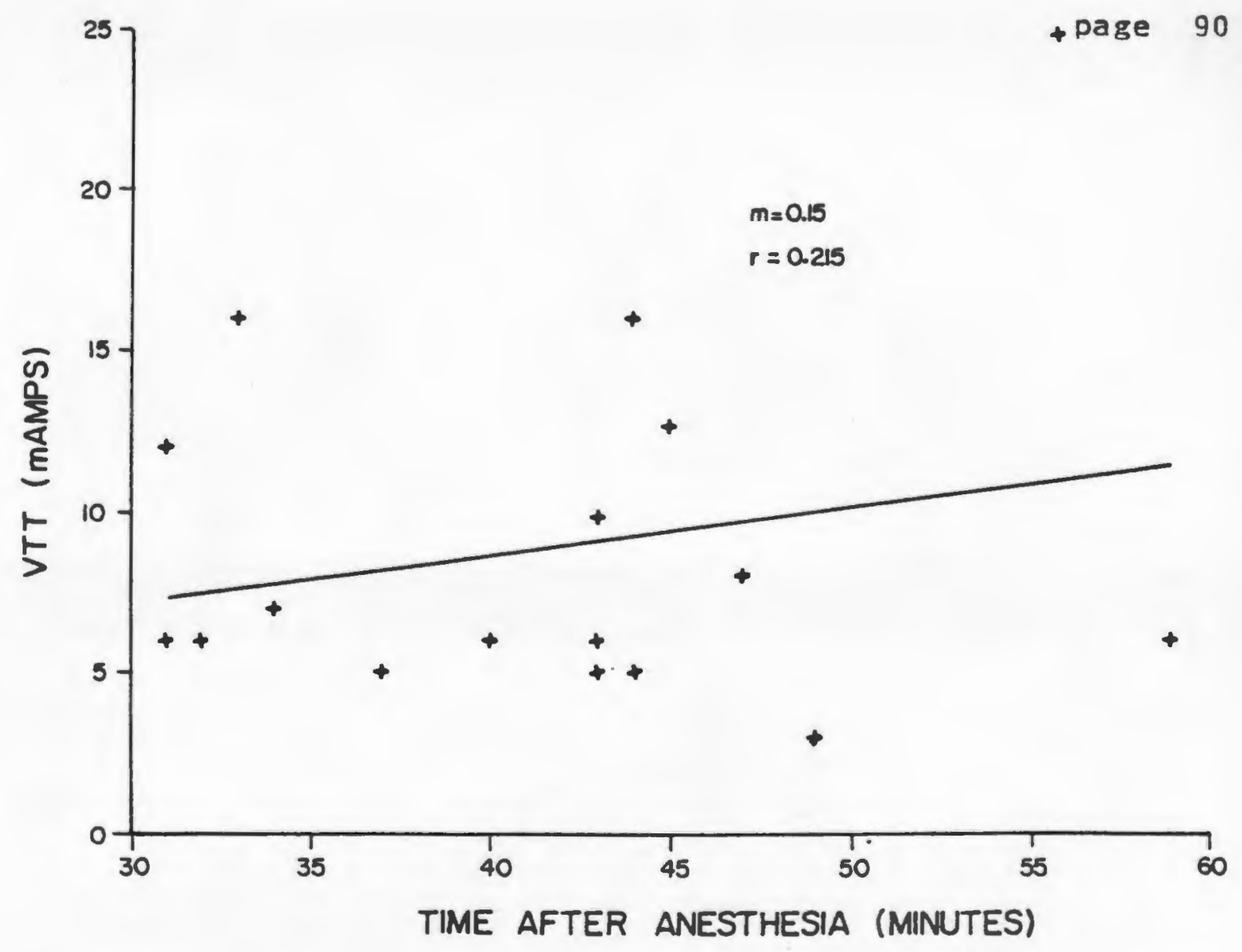

Figure 8. Correlation of Initial VTT With Time After Anes thesia

Initial VT thresholds following an oral injection and subsequent anesthesia are shown not to be correlated with the interval between anesthesia administration and VTT determination. This data is from rats treated with water for 10 weeks. 


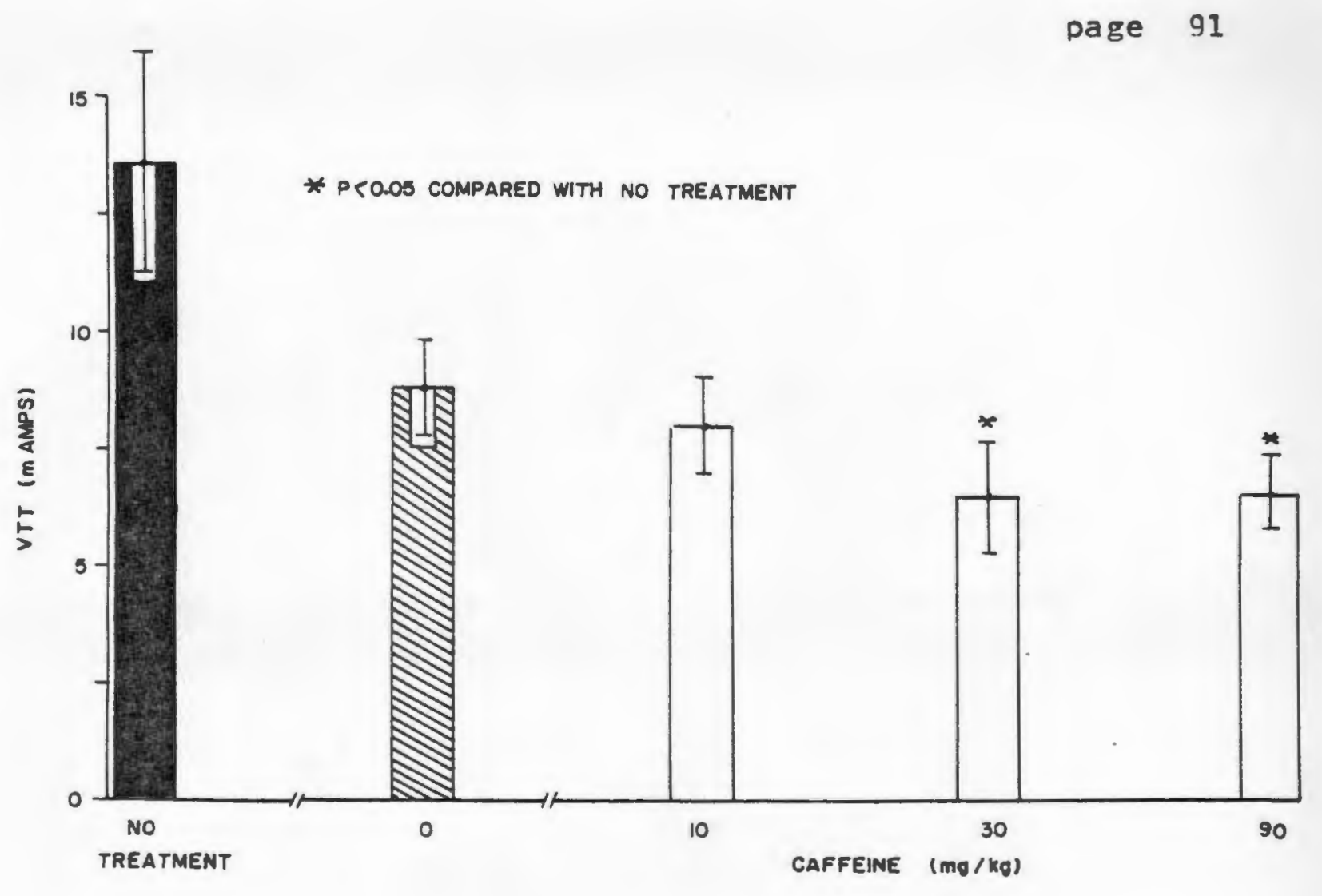

Flgure 9. Effect of Acute Caffelne Injection on VTT

VTT threshold following a single oral injection $(2 \mathrm{ml} / \mathrm{kg})$ of water or caffelne. Values are mean \pm SEM for 6 rats/group. Treatment with caffeine at 30 or $90 \mathrm{mg} / \mathrm{kg}$ significantly reduced VTT when compared to water treated rats (stripped bar) ( $p$ (0.1). 
threshold in drug treated animals $(90 \mathrm{mg} / \mathrm{kg})$ was $75 \%$ of their water treated counterparts $(p<0.1)$. Caffeine administered at a dose of $30 \mathrm{mg} / \mathrm{kg}$ produced a similar reduction whereas the $10 \mathrm{mg} / \mathrm{kg}$ dose caused only a small change $(-9 \%)$.

Acute caffeine administration also produced a dose related tachycardia. Water treated rats had an initial heart rate (i.e. after anesthesia, thoracotomy and electrode placement) of $236 \pm 11$ beats per minute. In caffeine treated rats $(10,30$ and $90 \mathrm{mg} / \mathrm{kg})$ heart rate was increased to $274 \pm 12$ beats per minute, $292 \pm 43$ beats per minute and $292 \pm 29$ beats per minute respectively. The fact that the 2 larger doses of caffeine had the same effects on both heart rate elevation and VTT reduction should be noted.

Effect of Dally Caffeine Treatment on VTT

A. Chronic Caffeine Ireatment Altered the Effect of Acute Caffeine challenge on VTT

This sub-section will present results only from groups of rats treated with the same solution prior to and on the day of VTT testing. The combined effect of chronic caffeine pretreatment and acute water challenge on threshold will be presented in the following 
sub-section of results.

Daily oral injections with caffeine $(90 \mathrm{mg} / \mathrm{kg})$ for periods of 8 or 10 weeks produced an increase in threshold as compared with their water treated counterparts (Figure 10). There was no difference between thresholds of animals treated for 2 or 4 weeks. but rats treated with caffeine for 8 or 10 weeks had thresholds more than twice as large as those treated with water ( $p<0.1$ and $p<0.01$ respectively). This progressive increase in threshold with progressively longer treatments was not seen with smaller doses of caffeine.

Following 8 or 10 week treatment, the relative increase in VTT seen with caffeine administration was dose related. For example, following 8 weeks of treatment at $10 \mathrm{mg} / \mathrm{kg}$, caffelne elevated the threshold by $29 \%$ as compared to the group treated with water for the same time period. At a dose of $30 \mathrm{mg} / \mathrm{kg}$, the elevation was $60 \%$ greater than control values. With the highest dose of caffeine rats yielded VTT's some 2.4 times greater than their water treated counterparts. The dose-response effect of subchronic caffeine treatment on subsequent VTT measurement is presented in Figure 11.

There was no dose dependent trend in the effect of chronic caffeine treatment on heart rate. Two way analysis of variance on all of the heart rate data also 


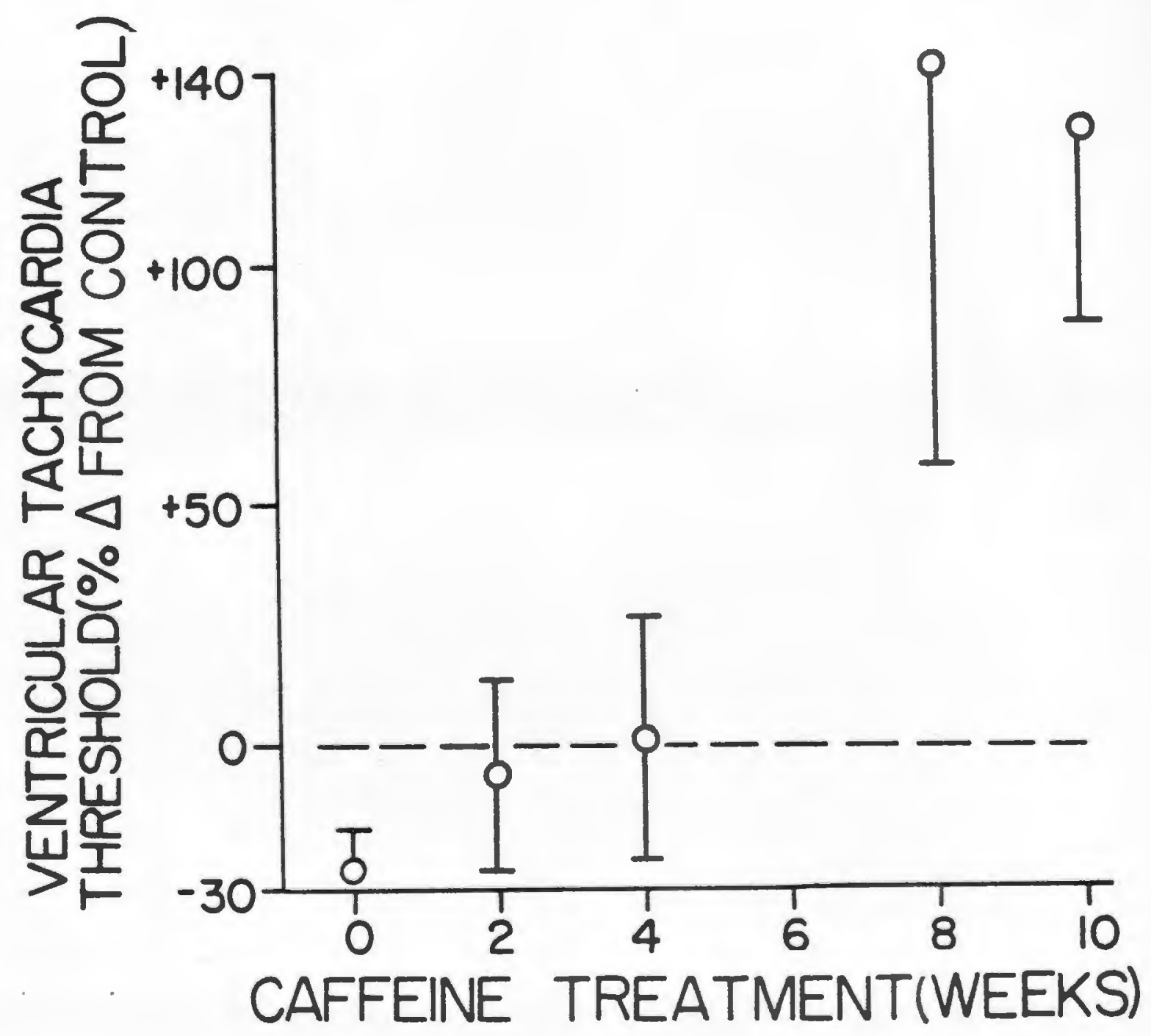

Figure 10. Reversal of the Effect of Acute Caffeine Injection on VTT Following Dally Caffeine Treatment

VTT thresholds of rats treated with caffeine ( 90 $\mathrm{mg} / \mathrm{kg} / \mathrm{day}$ ) were compared with rats treated with water for the same perlods of time. Single acute treatment is labelled as '0 weeks'. Caffeine treated rats were challenged with caffeine. Water treated rats were challenged with water. Means \pm SEM for groups of 6 rats. 
page 95

substantlated that the duration of caffelne treatment (i.e. acute vs, chronic) caused no significant change in heart rate.

The VTT results just presented are in dramatic contrast to the effect of single, acute caffeine injections on threshold. The biphaslc alteration in threshold was seen in Figure 10, where caffeine ( 90 $\mathrm{mg} / \mathrm{kg}$ ) caused a reduction in threshold when given acutely $(25 \%)$, but increased threshold (by more than $100 \%$ ) when administered daily for 8 or 10 weeks. Two of four week treatment annulled the acute reduction in threshold caused by caffelne challenge treatment, but did not produce any increase in VTT over control values. The chronic treatment-induced reversal of caffeine's arrhythmogenic action is summarized in Figure 12. The dose dependent increase in threshold in the chronically treated groups is clear. The progresslve reduction in VTT with increasing doses of acutely administered caffeine cannot be shown to be dose dependent (regression coefficient $=0.2$ ). As mentioned earlier, analysis of variance was performed on the threshold data to test whether the dose of caffeine had a significant effect, whether the duration of treatment altered VTT and whether there was any interaction between the two variables. The results of the test, presented in Table IV demonstrate that both factors alter threshold in and of themselves, 


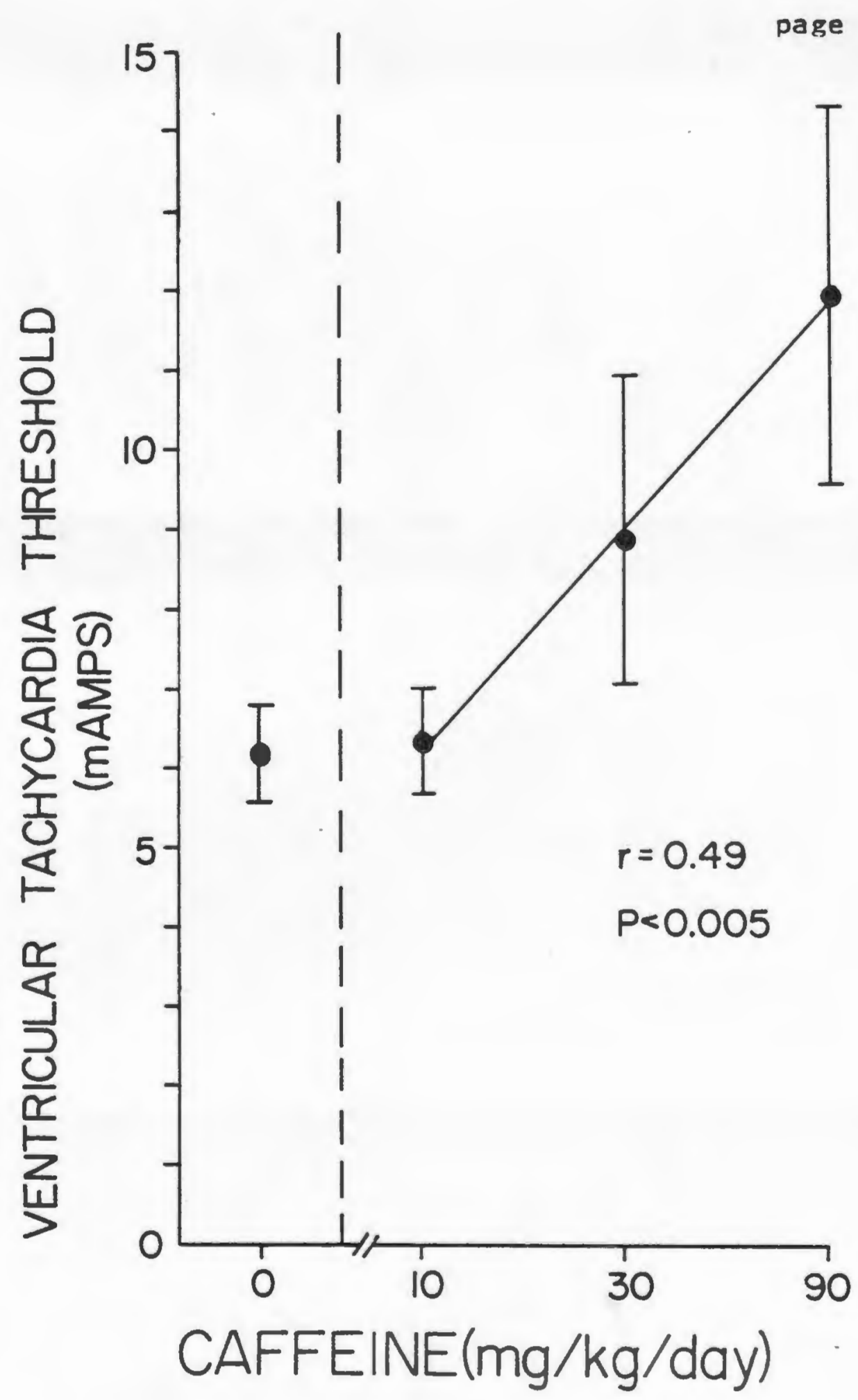

Figure 11. Dose Dependency of Chronic Dally Caffeine Treatment on Subsequent Elevation of VTT

Dally oral caffeine administration for 8 or 10 weeks followed by an acute caffeine challenge was associated with an elevation in VTT. The increase in VTT was dose related. (Data pooled from 8 and 10 week treatment groups). 


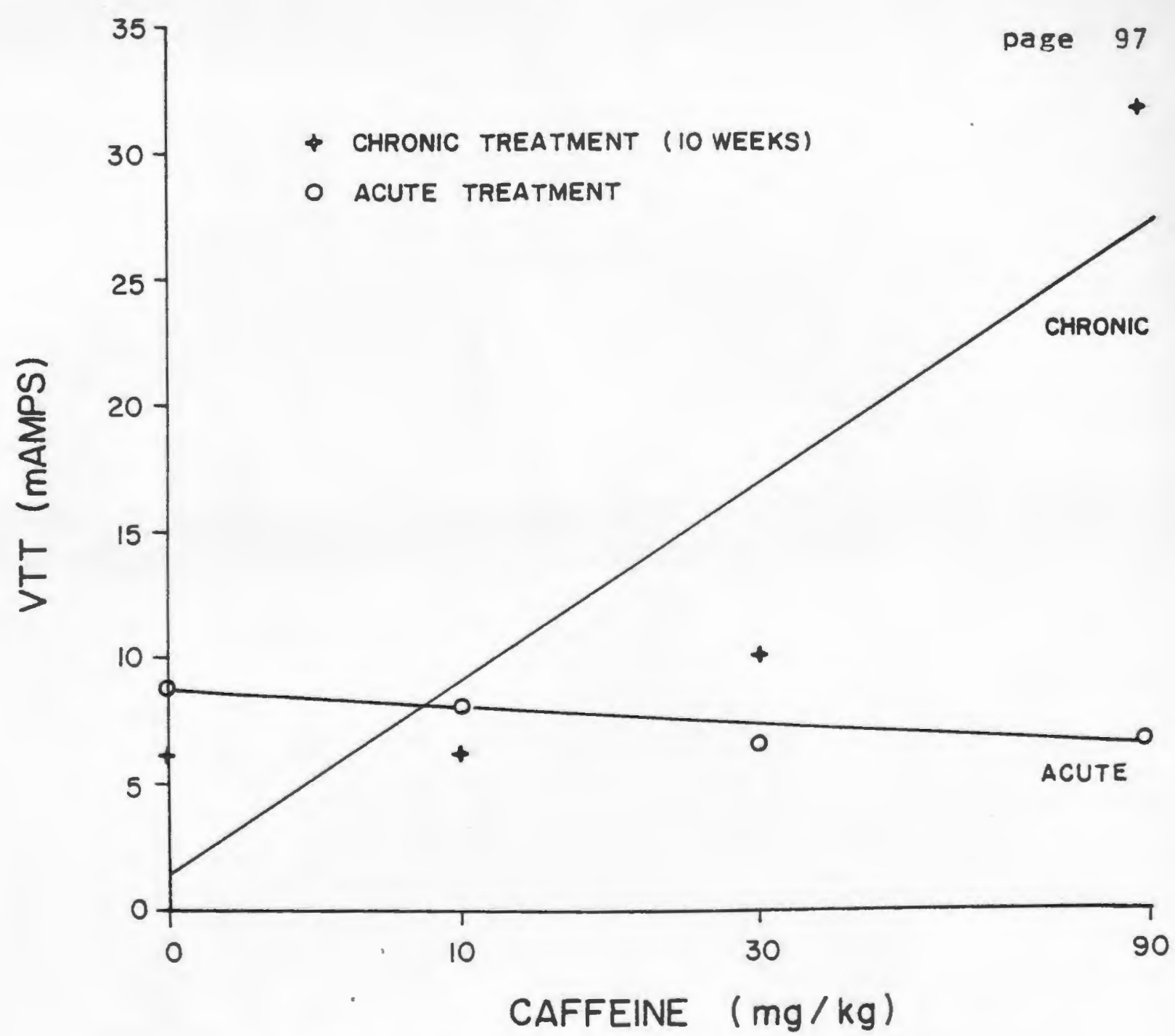

Figure 12. The Effect of Acute vs, Chronic Caffeine Treatment on VTT

+ VT thresholds of rats treated dally with caffeine for 10 weeks. Prior to VTT determination each rat recelved a challenge injection of the same caffeine dose administered previously.

- VT thresholds of rats administered a single injection of water or caffeine just prior to VTT determination.

Each point is the mean threshold of 6 rats. 


\section{TABLE IV}

\section{Analysis of Variance of The Effects of Caffelne}

Treatments For Different Time Periods On VTT

\begin{tabular}{lccccc}
$\begin{array}{l}\text { Source } \\
\text { of } \\
\text { Variation }\end{array}$ & $\begin{array}{c}\text { Sums } \\
\text { of } \\
\text { Squares }\end{array}$ & $\begin{array}{c}\text { Degrees } \\
\text { of } \\
\text { Freedom }\end{array}$ & $\begin{array}{c}\text { Mean } \\
\text { Squares }\end{array}$ & $\begin{array}{c}F \\
\text { Values }\end{array}$ & $\begin{array}{c}P \\
\text { Values }\end{array}$ \\
\hline $\begin{array}{l}\text { Caffeine } \\
\text { Treatments* }\end{array}$ & 828 & 3 & 273 & 9.97 & $<0.05$ \\
$\begin{array}{l}\text { Weeks of } \\
\text { Treatment* }\end{array}$ & 986 & 3 & 329 & 11.96 & $<0.05$ \\
$\begin{array}{l}\text { Treatment by Week } \\
\text { Interaction }\end{array}$ & 1766 & 9 & 196 & 7.14 & $<0.05$ \\
$\begin{array}{l}\text { Error } \\
\text { Total }\end{array}$ & 2199 & 80 & 27 & -- & -- \\
\hline
\end{tabular}

* Water or caffeine $(10,30$, or $90 \mathrm{mg} / \mathrm{kg})$

* Acute or 4,8 , or 10 weeks 
TABLE $\underline{Y}$

Summary of VTT Data and

LSD Test of Significant Differences

\begin{tabular}{cllll}
$\begin{array}{r}\text { CAFFEINE } \\
\text { DOSE }\end{array}$ & 0 & \multicolumn{2}{c}{ VTT in m AMPS $*$} \\
\cline { 3 - 5 } & & & & \\
\hline 0 & 8.8 & 12.2 & 5.2 & \\
& \pm 1.0 & \pm 2.1 & \pm 0.6 & \pm 0.2 \\
& 8.0 & 9.5 & 6.7 & 6.2 \\
10 & \pm 1.1 & \pm 2.1 & \pm 0.7 & \pm 1.0 \\
& 6.5 & 12.7 & 8.3 & 10.0 \\
30 & \pm 1.2 & \pm 1.5 & \pm 1.0 & \pm 2.2 \\
& 6.6 & 10.7 & 12.5 & 32.0 \\
90 & \pm 0.8 & \pm 1.4 & \pm 4.3 & \pm 4.8 \\
& & & &
\end{tabular}

* Means \pm SEM of 6 rats.

Least Significant Difference $(L S D)=s\left(1 / n_{1}+1 / n{ }^{2}\right)^{1 / 2} \times t$ where $s=$ (mean square of ANOVA error term)

$n_{1}$ and $n_{2}=$ number of rats in the experimental groups being compared. $t=t$ value: chosen in this case as the value at which a $95 \%$ confidence limit is assumed and the degrees of freedom is equal to the sum of the degrees of freedom minus that of the error term (i.e. 15).

Thus,

$$
\text { LSD }=5.2424 \times 0.577 \times 2.131=6.45
$$

Threshold values which differ by more than $6.45 \mathrm{~m}$ AMP are significantly different $(p<0.05)$ according to this test. 
page 100

and that they also interact in some additive fashion. The least significant difference was calculated from the analysis of variance data and applied to analyze differences in VTT between groups (Table V). Again. following 8 and 10 weeks of treatment, caffeine $(90$ $\mathrm{mg} / \mathrm{kg}$ ) increased the VTT.

B. The Effect of Chronic Caffeine Treatment Combined With Acute Water Challenge on VTI

VT thresholds were determined in 3 groups of rats. Two groups ( $A$ and $B$ ) received chronic daily caffeine treatment ( $90 \mathrm{mg} / \mathrm{kg} / \mathrm{day}, \mathrm{p.o.})$ and the third (group C) recelved water injections each day. Following the ten week treatments, one chronic caffeine group was challenged with a bolus of caffeine $(90 \mathrm{mg} / \mathrm{kg}, \mathrm{p.0.})$, while the other (group B) was administered water prior to cardlac vulnerablitity testing. The chronlc water treated group (C) was also challenged with water.

In both groups $A$ and $B$, threshold was elevated when when compared with the VTT of rats treated chronically with water (group C). The increase in VTT in Group A was 138\% and in Group B, $89 \%$. The elevations in threshold demonstrated in the two chronic caffeine treated groups were not significantly different from each other. Thus chronic caffeine was associated with a similar increase in VTT whether the rat was challenged with caffeine or 
water.

\section{Effect of Chronic Caffeine Treatment on Isoproterenol Induced Tachycardla}

After treatment for 10 weeks with caffeine $(90$ $\mathrm{mg} / \mathrm{kg}$ ) rats tended to show an attenuated increase in heart rate with increasing doses of isoproterenol. This effect, demonstrated in Figure 13, was only evident at the highest doses of isoproterenol. Each point on the curve represents the results of only 4 rats - two caffeine treated and one chronic water treated animal had died prior to testing. A second water treated rat did not show a dose dependent tachycardia and was therefore not included in the study. 


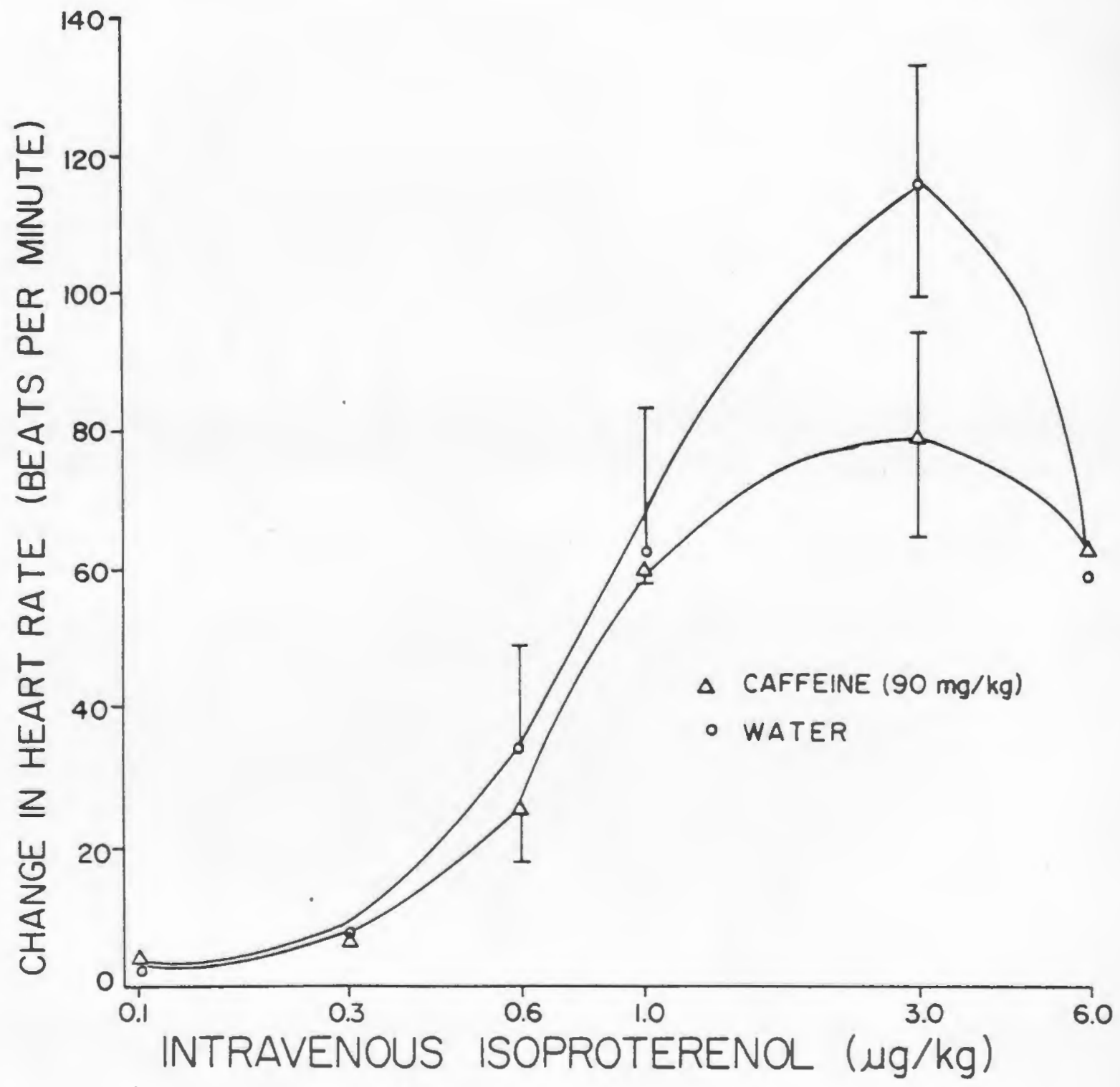

Figure 13. Alteration of I soproterenol Chronotropy By Chronic Caffeine Pretreatment

Rats were treated with oral injectlons of caffeine or water for 10 weeks. Following bilateral vagotomy, each animal was tested with increasing doses of isoproterenol. Mean \pm SEM, $n=4$ rats/group. 
page 103

\section{DISCUSSION}

The results of these experiments indicate that oral caffeine administration alters the vulnerability of rat ventricle to tachyarrhythmia. In agreement with the findings of Bellet and coworkers (1972), acute injection of the drug $(90 \mathrm{mg} / \mathrm{kg})$ reduced the threshold to arrhythmia. The dose dependent tachycardia associated with single caffeine injection suggests a correlation between elevation of sympathetic tone to the periphery and caffeine - induced reduction in VTT. This assessment is also in agreement with the finding that beta adrenergic blockade prevented the acute reduction in threshold by caffeine (Bellet et al. 1972).

The oral injection of water was also associated with a reduction in VTT. The magnitude of the reduction was significantly less than that associated with caffeine ingestion. Thus the caffeine related reduction in threshold was in addition to that caused by the injection process.

The acute injection process may be associated with a reduced threshold as a result of a generalized stress reaction. The effect of stress in augmenting cardiac vulnerability has previously been demonstrated by Lown et al. (1973) and Corbalan et al. (1974). The threshold for 
page 104

repetitive response was reduced to $67 \%$ of control values when dogs were placed in a stressful environment. Selective beta-1 adrenergic blockade with tolamolol hydrochloride prevented this reduction in threshold associated with psychologic stress (Lown and Verrier, 1976). Increased ventricular vulnerability in the setting of stress thus appears to also be mediated by sympathetic nervous system activity. Sympathetic tone, increased as a result of the injection process, would be further augmented by caffeine administration. This combined activation of the sympathetic limb of the autonomic nervous system seems to mediate the additive reduction in VTT by caffeine and the injection process.

The reduction in VTT following a single caffeine injection is maximal at a dose of $30 \mathrm{mg} / \mathrm{kg}$. The tachycardic effect of acute oral caffeine administration is also maximal at this same dose. At $10 \mathrm{mg} / \mathrm{kg}$, caffeine does not significantly alter either of these parameters. Rough conversions of these doses to human equivalent doses (with rat considered one tenth as sensitive as man) suggest that the caffeine content of as 1 ittle as 2 cups of coffee may increase the vulnerability of the human heart to arrhythmia. A more conservative estimate of the conversion factor (i.e. no difference in sensitivity) would predict that this dose in rat represents that found in 21 cups of coffee $(30 \mathrm{mg} / \mathrm{kg} \times 70 \mathrm{~kg}$ body weight $/ 100$. 
page 105

$\mathrm{mg} /$ cup). Based on the rough conversion factor reported by Vitello and Woods (1975), this dose represents the caffeine content in 10-15 cups of coffee.

Dally subacute administration of caffeine (for 2 or 4 weeks) prevented the reduction in VTT associated with caffeine injection just prior to threshold measurement. Tolerance occurs to many effects of the drug (see Literature Review). In a similar manner subacute administration of caffeine may make the rat tolerant to the VTT reducing action of caffeine. Four week treatment with oral water injections produce rats whose thresholds are the same as untreated controls (Table V). Thus tolerance has developed to the injection process as well. stress adaptation may play a part in this demonstration of tolerance to the effect of the injection process and caffeine administration on ventricular vulnerability. Following 32 days of restraint stress, male albino rats demonstrated adaptation to the effects of stress on brain serotonin content, norepinephrine content, blood corticosterone levels, and various organ welghts (Rosecrans and De Feo, 1965). The physical and psychologic stress related to the injection process may well be the same as that associated with restraint stress. The action of caffeine administration to increase brain norepinephrine turnover rates and decrease brain serotonin rates (see Literature Review), would be 
construed as increases in brain serotonin levels and a reduction in NE levels - i.e. the same effects associated with restraint stress (Rosecrans and De Feo, 1965). Thus caffeine administration may, to a certain extent, be interpretted as producing a stress reaction. Tolerance to the effect of caffeine on VTT may therefore be due to pharmacologic tolerance (i.e. the increased metabolism and excretion or decreased effect of the drug at the receptor) and/or adaptation to stress associated with caffeine administration.

Subchronic caffeine treatment $(90 \mathrm{mg} / \mathrm{kg} / \mathrm{day})$ for 8 or 10 weeks was associated with a two fold increase in VTT when compared with that of control rats treated with oral water injection for the same periods of time (Figure 10). Smaller doses of caffeine produced correspondingly less elevation in threshold (Figure 11). This reversal of the VTT reducing effect of acute caffeine injection suggests that chronic caffeine administration causes some radically different effect than does the acute or even subacute administration of the drug. This effect of chronic caffeine administration on vulnerability cannot be interpreted merely as tolerance, since tolerance implies compensation which prevents the agent from producing its normal effect. In this case caffeine produces an elevation in VTT, regardless of the challenge dose, thus suggesting an effect which is just the 
page 107

opposite of that seen with single injection. Chronic administration may reduce cardiac vulnerability by altering certain receptor sites.

Chronic caffeine treatment was shown to reduce the maximal chronotropic effect of isoproterenol, but not to shift the dose-response curve. (Figure 13). Interpretation of these findings suggest that there is no reduction in the sensitivity of the cardiac beta adrenergic receptor. Such an effect would be reflected as a shift to the right of the dose response curve. Conversely, the reduction in the maximal effect of isoproterenol on heart rate suggests that there has been a reduction in the beta receptor population mediating isoproterenol induced tachycardia.

Reduction in cardiac beta receptor population could explain the demonstrated elevation in VTT. Withdrawal of sympathetic tone to the heart reduces its vulnerability to fibrlllation (see review by Lown et al.e 1977). The reduction on cardiac beta receptor concentration would be equivalent to an anatomical and functional reduction of tonic sympathetic input to the heart. The conclusion that this mechanism is the only explanation of the chronic caffeine related elevation in threshold cannot be made based on the results of this study. The limited number of rats in the isoproterenol dose response experiment were too few to demonstrate statistical 
page 108

significance of the data trend. More importantly, other sites or mechanisms of action of caffeine may also reduce cardiac vulnerability. Speculation as to possible additional mechanisms could include at least the following: increased vagal traffic as a result of caffeine's actions on midbrain vagal centers or increased phosphodiesterase activity (due to induction of new enzyme formation) resulting in reduced $c$ AMP levels within the heart. Both of these effects would reduce vulnerability to VF according to presently held theories (see Literature Review). 
page 109

\section{SUMMARY AND CONCLLUSIONS}

Clinical studies examining the correlation of coffee consumption on incidence of acute $M I$ and subsequent death (presumably the result of VF) have falled to clearly examine the effect of caffeine on vulnerability to VF. One previous laboratory study (Bellet et all. 1972) demonstrated that caffeine infusion (12.5 mg/kg, i.v.) reduced fibrillation threshold. Again, such a study does not directly determine the effect of chronic eral caffeine administration, i.e. the manner in which caffeine is consumed by man, on the susceptibility to life-threatening dysrhythmia.

This study represents the first reported laboratory experiments examining the effects of daily oral caffeine administration on cardiac vulnerability to ventricular tachyarrhythmia. The effects of acute and chronic oral administration of caffeine on the ventricular tachycardia threshold was determined. The VTT in rat was proposed as an index of the vulnerability of larger hearts to fibrillation.

The results of this investigation suggest that a single, oral injection of caffeine $(30$ or $90 \mathrm{mg} / \mathrm{kg})$ increases susceptibility of the heart to arrhythmia. The caffeine effect is in addition to the general stress 
page 110

effect of the oral injection process. The magnitude of the effect is simllar to that demonstrated by Bellet and coworkers. Dose related tachycardia accompanied the fall in VTT suggesting a heightening of sympathetic tone to the periphery.

In marked contrast, daily caffeine administration for 8 or 10 weeks followed by the same acute test injection was associated with a greater than two fold increase in VTT when compared with water treated controls. This reversal of acute drug effect was dose dependent. Following 2 or 4 week caffeinetreatment, acute caffeine injecvtion no longer reduced VTT.

In an attempt to explain these results, this study indicated that chronic caffeine administration tended to attenuate the maximal chronotropic effect of isoproterenol. However, this tendency was not demonstrated with certainty, because statistical significance was not reached (presumably due to the small number of subjects). The effect of long term caffeine treatment may be to reduce the beta adrenergic receptor population in the heart and/or brain.

It is concluded that single caffeine administration, at doses corresponding to that consumed by man in 6-8 cups of ground coffee, increased the susceptibility of rat heart to ventricular tachyarrhythmia. Pretreatment for 8 or 10 weeks with 
page 111

similar caffeine doses prevented the increased susceptibility to arrhythmia and, in fact, had a protective effect by reducing the vulnerabllity to life threatening arrhythmia. 
page 112

\section{REFEREIICES}

Allen, J.D., Pantridge, J.F. and Shanks, R.G.: The effects of practolol on the dysrhytmias complicating acute ischemic heart disease. Amer. J. Med. 58: 199-208, 1975 .

Aravindakshan, V. and Gettes, L.S.: Effects of bretylium and lidocaine on ventricular fibrillation in the isolated rabbit heart. Cardiovasc. Res. 9: 19-28, 1975 .

Armitage, A.K., Burn, J.H. and Gunning, A.J.: Ventricular fibrillation and ion transport. Circ. Res. 5: 98-104, 1957 .

Axelrod, J. and Relchenthal, J.: The fate of caffelne in man and a method for its estimation in biological material: J. Pharmacol. Exp. Ther. 107: 519-523, 1953.

Axelrod, P.J., Verrier, R.L. and Lown, B.: Vulnerability to ventricular fibrlllation (VF) during acute coronary occlusion and release. Amer. J. Cardiol. 35 : $775-782,1975$.

Bacaner, M.B.: Quantitative comparison of bretylium with other antifibrillatory drugs. Amer. J. Cardiol. 21: $504-512,1968$.

Beattie, J., Brown, G.R. and Long, C.N.H.: The Vegatative Nervous system. (Baltimore: Williams and Wilkins, 1930) p 249 .

Bellet, S., Horstmann, E., Roman, L. R., De Guzman, N. T., Kostis, J. B.: Effect of caffeine on the ventricular fibrillation threshold in normal dogs and dogs with acute myocardial infarction. Amer. Heart $J$. 84: $215-227,1972$.

Bellet, S., Roman, L., De Castro, O., Kim, E.K. and Kershbaum, A.: Effect of coffee ingestion on catecholamine release. Metabolism 18: 288-291, 1969.

Berkowitz, B.A.. Tarver, J.H. and Spector, S.: Release of norepinephrine in the central nervous system by theophylline and caffeine. Eur. J. Pharmacol. 10: $64-71,1970$.

Berkowitz, B.A. and Spector, S.: Effect of caffeine and 
theophylline on peripheral catecholamines. Eur. J. Pharmacol. 13: 193-196, 1971.

Blinks, J.R., Olson, C.B., Jewell, B.R. and Braveny, P.: Influence of caffeine and other methylxanthines on mechanical properties of isolated mammalian heart muscle. Circ. Res. 30: 367-392, 1972.

Blumenthal, B. and Tribe Oppenheimer, E.: Method for the study of ventricular fibrillation. Amer. Heart J. 18: $363-367,1939$.

Boehm, R.: Naunyn - Schmledeberg's Arch. Exp. Path. Pharmak. 3: 216, 1875.

Bond, H.W., Mauger, K. and De Feo, J.J.: Interactions in the toxicity of pyrethrum, synergists, and other chemicals to mammals. In Pyrethrum. The Natural Insecticide, J.E. Casida, ed. (New York: Academic Press, 1973) pp 177-194.

Brooks, C.M., Hoffman, B.F., Suckling, E.E. and Orias, E.: Excitability of the Heart. (New York: Grune and Stratton, 1955).

Burg, A.W.: How much caffeine in the cup? Tea and Coffee J. Jan., 1975.

Burnstock, G.: Purinergic nerves. Pharmacol. Rev. 24: $509-581,1972$.

Butcher, R.W. and Sutherland, E.W.: Adenosine 3',5'-phosphate in biological materials. J. Biol. Chem. 237: 1244-1250, 1962 .

Carlson, A., Lindquist, M. and Magnusson, T.: On the biochemistry and possible functions of dopamine and noradrenaline in brain. in Adrenergic Mechanisms, Ciba Foundation Symposium, J.R. Vane, G.E.W. Wolstenholme and M. O' Connor, eds. (London: J.A. Churchill, 1960).

Carrodi, H., Fuxe, K, and Jonsson, G.: Effects of caffeine on central monoamine neurons. J. Pharm. Pharmac. 24: 155-158, 1972 .

Chiba, S., Kubota, K. and Hashimoto, K.: Inhibition of the negative chronotropic action of adenosine by caffeine in the dog. Eur. J. Pharmacol. 21: 281-285. 1973. 
Colton, t.. Gosselin, R.E. and Smith, R.P.: The tolerance of coffee drinkers to caffeine. Clin. Pharmacol, and Ther. 9: 31-39, 1968 .

Corbalan, R., Verrier, R.L. and Lown, B.: Psychologic stress and ventricular arrhythmias during myocardial infarction in the consclous dog. Amer. J. Cardiol. 34: 692-696, 1974 .

Das, P.K. and Sinha, P.S.: Effect of physostigmine on ventricular fibrillation and myocardial glycogen in hypothermic dogs. Brit. J. Pharmac. 44: 391-396, 1972.

Dawber, T.R., Kannel, W.B. and Gordon, T.: Coffee and cardiovascular disease. N. Engl. J. Med. 291: $871-874,1974$.

De Boer, S.: On the fibrillation of the heart. J. Physiol. (London) 54: 400-409, 1920-1921.

de Gubareff, T. and Sleator, W. Jr.: Effects of caffeine on mammalian atrial muscle, and its interaction with calcium. J. Pharmacol. Exp. Ther. 148: 202-214, 1965.

De Schaepdryver. A.F.: Physio-pharmacological effects on suprarenal secretion of adrenaline and noradrnaline in dogs. Arch int. Pharmacodyn. 119: 517-518, 1959.

Desilva, R., Verrier, R.L. and Lown, B.: The effects of psychological stress and vagal stimulation with morphine on vulnerability to ventricular flbrillation (VF) in the conscious dog. Amer. Heart J. 1977 (in press).

Dikshit, B.B.: The production of cardiac irregularities by excitation of the hypothalmic centres. J. Physiol. (London) 81: 382-394, 1934.

Ederstrom, H.E.: Ventricular fibrillation susceptibility as related to heart size and maturity (abstr). Fed. Proc. 35: 221, 1376.

Einbrodt: Uber Herzreizung und ihr Verhaeltnis zum blutdruck. Akademie der Wissenschaften (Vienna) Sitzungsberichte 38: 345-359, 1859 .

Engelman, T.W.: Uber den einflus der systole auf die motorische leistung in der herzkammer mit bemerkungen zur theorie allorhythmischer herstoerungen. Pfiug. Arch. ges. Physiol. 62: 543, 1896. 
Erichsen, J.E.: On the influence of the coronary circulation on the action of the heart. London Med. Gazette 30: 561-564, 1842 .

Ferris, L., King, B.G., Spence; P.W. and Williams, H.B.: Effect of electrical shock on the heart. Electrical Engr. 55: 498, 1936 .

Galli, C. and Spagnuolo, C.: Distribution of caffeine and metabolites in brain and liver subcellular fractions in the rat. Pharmacol. Res. Commun. 7: 125-132, 1975.

Gamble, 0.W. and Cohn, K.: Effect of propranolol, procainamide, and ildocaine on ventricular automaticity and reentry in experimental myocardial infarction. Circulation 46: 498-506, 1972.

Garrey, W.E.: The nature of fibrillatary contraction of the heart; its relation to tissue mass and form. Amer. J. Physiol. 33: 397-414, 1914.

Garza, D.A., White, F.C., Hall, R.E. and Bloor, C.M.: Effect of coronary collateral development on ventricular fibrillation threshold. Basic Res. Cardiol. 69: 371-378, 1974.

George, A., Spear, J.F. and Moore, E.M.: The effects of digitalis glycosides on the ventricular fibrillation threshold in innervated and denervated canine hearts. Circulation, 50: 353-359, 1974.

Gerst, P.H., Fleming, W.H. and Malm, J.R.: Increased susceptibility of the heart to ventricular fibrillation during metabolic acidosis. Circ. Res. 19: $63-70,1966$.

Gold, H., Travell, J. and Modell, W.: The effect of theophylline with ethylenediamine (aminophylline) on the course of cardiac infarction following experimental coronary occlusion. Amer Heart J. 14: $284-295,1937$.

Gould, L., Venkataraman, K., Goswami, M. and Gomprecht, R.F.: The cardiac effects of coffee. Angiology 24: $455-463,1973$.

Greiner, T.H. and Garb, S.: The influence of drugs on the irritability and automaticity of heart muscle. J. Pharmacol. Exp. Ther. 98: 215-223, 1950.

Grumbach, L., Howard, J.W. and Merril1, V.I.: Factors 
related to the initiation of ventricular fibrillation in the isolated heart, effect of calcium and potassium. Circ. Res. 2: 452-459, 1954.

Han, J. and Moe, G.K.: Nonunlform recovery of excitability in ventricular muscle. Circ. Res. 14: $44-60,1964$.

Han, J.. Garcia de Jalon, P. and Moe, G.K.: Adrenergic effects on ventricular vulnerability. Circ. Res. 14: 516-524, 1964 .

Han, J., Millet, D., Chizzonitti, B. and Moe, G.K.: Temporal dispersion of recovery of excitability in atrium and ventricle as a function of heart rate. Amer. Heart J. 71: 481-487, 1966a.

Han, J., Garcia de Jalon, P.D. and Moe, G.K.: Fibrillation threshold of premature responses. Circ. Res. 18: 18-25, 1966b.

Harrison, L.A.. Harrsion, L.H. Jr., Kent, K.M. and Epsteln, S.E.: Enhancement of electrical stability of acutely ischemic myocardium by edrophonium. Circulation 50: 99-102, 1974.

Hellenbrecht, D. and Gortner, L.: Influence of isoprenaline and salbutamol on the threshold of electrically induced fibrillation in anesthetized guinea pigs. Naunyn - Schmiedeberg's Arch. Pharmacol. 287: 227-232, 1375 .

Hoff, H.E. and Nahum, L.H.: The nature of ventricular fibriliation following electric shock and its prevention by acetyl-beta-methyl choline chloride. Amer. J. Physiol. 110: 675-680, 1934.

Hoffa, M. and Ludwig, C.: Einige neune versuche uber herzbewegung. Ztschr. Rat. Med. 9: 107-144, 1850. 
Horowitz, L.N., Spear, J.F., Moore, E.N. and Rogers, R.: Effects of aminophyline on the threshold for initiating ventricular fibrillation during respiratory fallure. Amer. J. Cardiol. 35: 376-379, 1975.

Jick, H., Miettinen, O.S.. Neff, R.K.. Shapiro, S., Heinonen, O.P. and sloane, D.: Coffee and myocardial infarction. N. Engl. J. Med. 289: 63-67, 1973.

Jokela, S. and Vartiainen, A.: Caffeine poisoning. Acta Pharmacol. 15: 331-334, 1959.

Kannel, W.B.. Doyle, J.T., Mc Namara, P.M., Quickenton, $P$. and Gordon, T.: Precursors of sudden coronary death: factors related to the incidence of sudden death. Circulation 51: 606-613, 1975.

Karki, N.T.: The effects of changes in ion concentration on ventricular fibrillation induced electrically. J. Physiol. (London) 141: 366-376, 1958.

King, B.G.: The Effect of Electrical Shock on Heart Action with Special Reference to Varying Susceptiblitity in Different Parts of the Cardiac Cycle. Columbia University Thesls. (New York: Aberdeen Press, 1934).

Kukovetz, W.R. and Poch, G.: Cyclic AMP and inotropism as affected by stimulators of adenylate cyclase and inhibitors of phosphodlesterase. in Advances in Cyclic Nucleotide Research, vol. 5, P. Greengard and G.A. Robison, eds. (New York: Raven Press, 1975).

Le Roy, G.V.. Fenn, G.K. and Gilbert, N.C.: The influence of xanthine drugs and atropine on the mortality rate after experimental occlusion of a coronary artery. Amer. Heart J. 23: 637-643, 1942.

Levi, L.: The effect of coffee on the function of the sympathoadrenomedullary system in man. Acta Med. scand. 181: 431-438, 1967.

Levine, H.D.: Effect of quinidine sulphate in inhibiting ventricular fibrillation. Arch. Internal Med. 49: $808-815,1932$.

Levy, A.G.: Sudden death under light chloroform anesthesia. J. Physiol. 42: Iil, 1911.

Lown, B., Klein, M.D. and Hershberg, P.L.: Coronary and 
page 118

precoronary care. Amer. J. Medicine 46: 705-724, 1969.

Lown, B., Verpier, R. amd Corbalan, R.: Psychologic stress and threshold for repetetive ventricular response. Science 182: 834-836, 1973.

Lown, B. and Verrier, R.L.: Neural activity and ventricular fibriliation. N. Engl. J. Med. 294: $1165-1170,1.976$.

Lown, B., Verrier, R.L., and Rabinowitz, S.H.: Neural and psychologic mechanisms and the problem of sudden death. Amer. J. Cardiol. 39: 890-902, 1977.

Lubbe, W.F., Bricknel1, O.L. and Marzago, C.: Ventricular fibrillation threshold and vulnerable period in the isolated perfused rat heart. Cardiovasc. Res. q: $613-620,1975$.

Malliani. A., Schwartz, P.J. and Zanchetti, A.: A sympathetic reflex elicited by experimental coronary occlusion. Amer. J. Physiol. 217: 703-709, 1969.

Marcus, M.L.. Skelton C.L.. Prindle, J.H. Jr. and Epstein. S.E.: Potentiation of the inotropic effects of glucagon by theophyli ine. J. Pharmacol. Exp. Ther. 179: $331-337,1972$.

Mc Neil1, J.H. and Muschek, L.D.: Histamine effects on cardiac contractility, phosphorylase and adenyl cyclase. J. Molec. Cel1. Cardiol. 4: 611-624, 1972.

Platsuda, K.. Hoshi, T. and Kameyama, S.: Effects of aconitine on the cardiac membrane potential of the dog. Jap. J. Phyisol. 9: 419-429, 1959. 
Meek, W.J.. Hathaway, H.R. and Orth, O.S.: The effects of ether. chloroform and cyclopropane on cardlac automaticity. J. Pharmacol. Exp. Ther. 61: 240-252, 1937.

Moe, G.K., Mendez, C. and Valero, A.: Excitabillty recovery of early premature ventricular beats (abstr). Fed. Proc. 14: 102, 1955.

Hoe, G.K. and Abildskov, J.A.: Atrial fibrlilation as a self sustaining arrhythmia independent of focal discharge. Amer. Heart J. 58: 59-70, 1959.

Moe, G.K.. Abildskov, J.A. and Han, J.: Factors responsible for the initiation and maintenance of ventricular fibrillation. In, Sudden Cardiac Death. Edited by Surawicz, B. and Pellegrino, E.D. (New York: Grune and Stratton, 1964) pp 56-63.

Moore, E.N., Preston, J.B. and Moe, G.K.: Durations of transmembrane action potentials and functional refractory periods of canine false tendon and ventricular myocardium. Clrc. Res. 17: 259-273, 1965.

Moore, E.N. and Spear, J.F.: Ventricular fibrillation threshold - Its physlological and pharmacological importance. Arch. Intern. Med. 135: 446-453, 1975.

Murnaghan, M.F.: The effect of anoxia on the ventricular fibplilation threshold in the rabbit isolated heart. Brit. J. Pharmac. 54: 413-420, 1975.

Neff, N.H. and Costa, E.: The influence of monoamine oxidase inhibition on catecholamine synthesis. Life Sci. 5: 951-959, 1966.

Paul, 0., Lepper, M.D., Phelan, W.H., Dupertuls, W., Mac Millan, A. and Park, H.: A longitudinal study of coronary heart disease. Circulation 28: 20-31, 1963.

Peach, M.J.: Stimulation of release of adrenal catecholamine by adenosine $3^{\prime} 5^{\prime}$-cyclic monophosphate and theophylline in the absence of extraceliular calcium. Proc. Nat. Acad. Sci.. U.S.A. 59: 834-836. 1972.

Podzuweit, T., Lubbe, W.F. and Opie, L.H.: Cyclic adenosine monophosphate, ventricular fibrlllation, and antiarphythmic drugs. Lancet 1: 341-342, 1976.

Poisner, A.M.: Direct stimulant effect of aminophylline 
on catecholamine release from the adrenal medulla. Biochem. Pharmacol. 22: 469-475, 1973.

Prinzmetal, M., Corday, E., Brill, I.C., Oblath, R.W. and Kruger, H.E.: The Auricular Arrhythmias. (Sringfield, 111.: Charles C. Thomas, 1952).

Rall, T.W. and West, T.C.: The potentiation of cardiac intropic responses to norepinephrine by theophylline. J. Pharmacol. Exp. Ther. 139: 269-274, 1963.

Ritchie, J.M.: The Xanthines. in The Pharmacologic Basis of Therapeutics, L.S. Goodman and A. Gilman, eds. (New York: Macmillan, 1975).

Roberts, H.C. and Buja, L.M.: The frequency and significance of coronary artery arterlal thrombi and other observations in fatal acute myocardial infarction. Amer. J. Med. 52: 425-443, 1972.

Rosecrans, J.A. and De Feo, J.J.: The interrelationships between chronic restraint stress and reserpine sedation. Arch. int. Pharmacodyn. 157: 487-4.98, 1965.

Rotenberg, F.A., Verrier, R.L., Lown, B. and Sole, M.J.: Effects of clonidine on vuinerability to fibrillation in the normal and ischemic canine ventricle (abstr.). Fed. Proc. 36: 1002, 1977.

Rothberger, C.J. and Winterberg, H.: Das flimmern der herzkammern. Z. ges. Exp. Med. 4: 407-426, 1916.

Sant' Ambrogio, G., Mognoni, P. and Ventrella, L.: Plasma levels of caffeine after oral, intramuscular and intravenous administration. Arch. int. Pharmacodyn. 150: $259-263,1964$.

Scherf, D.: Studies on auricular tachycardia caused by aconitine administration. Proc. Soc. Exp. Biol. 54: $233-239,1947$.

Schmidt, R.F.: Versuche mit aconitin zum problem der spontanen erregungsbildung im herzen. Pflugers Arch. ges. Physiol. 271: 526-536, 1960 .

Schwartz, P.J., Snebold, M.G. and Brown, A.M.: Effects of unllateral cardiac sympathetic denervation on the ventricular fibrillation threshold. Amer. J. Cardiol. 37: 1034-1040, 1976.

Shen, T.C.R. and Simon, M.A.: The protecting action of 
page 121

novocaine upon chloroform-adrenalin ventricular fibrillation. Arch. Internat. Pharmacol. et Therap. 59: $63-74,1938$.

Shinohara, Y.: Ventricular fibrillation threshold VFRT in experimental coronary occlusion: comparitive studies on the effect of $G-1-K$ solution and some new antiarrhythmilc agents. Jap. Circ. J. 32: 1269-1281, 1968 .

Shumway, N.E., Johnson, J.A. and Stish, R.J.: The study of ventricular fibrillation by threshold

determinations. J. Thoracic Surg. 34: 643-653, 1957.

Sidowski, J.B., ed.: Experimental Methods And Instrumentation in Psychology. (New York, Mc Graw Hill Book Co., 1966) p 120 .

Skinner, J.E., Lie, J.T. and Entman, M.L.: Modification of ventricular fibrillation latency following coronary artery occlusion in the conscious pig. The effects of psychological stress and beta-adrenergic blockade. Circulation 51: 656-667, 1975 .

Smirk, F.H.. Nolla - Panades, J. and Wallis, T.: Experimental ventricular fiutter and ventricular paroxysmal tachycardla. Amer. J. Cardiol. 14: 79-88, 1964 .

Smirk, F.H. and Palmer, D.G.: A myocardial syndrome with particular reference to the occurence of sudden death and of premature systoles interrupting antecedent $T$ wave. Amer. J. Cardiol. 6: 620-629, 1960.

Spear, J.F., Moore E.N. and Horowitz, L.N.: Effect of current pulses delivered during the ventricular vulnerable period upon the ventricular fibrillation threshold. Amer. J. Cardiol. 32: 814-822, 1973.

Starmer, C.F., Whalen, R.E. and Mc Intosh, H.D.: Hazards of electric shock in cardiology. Amer. J. Cardiol. 14: $537-546,1964$.

Sugimoto, T., Schaal, S.F. and Wallace, A.G.: Factors determining vulnerability to ventricular fibrillation induced by 60-cps al ternating current. Circ. Res. 21: $601-603,1967$.

Surawicz, B., Gettes, L.S. and Ponce - Zumino, A.: Relation of vulnerability to ECG and action potentlal characteristics of premature beats. Amer. J. Physiol. 
page 122

212: $1519-1528,1967$.

Surawicz, B.: Ventricular fibrillation. Amer. J. Cardiol. 28: $268-287,1971$.

Szekeres, L. and Papp, Gy. J., eds.: Experimental Cardiac Arrhythmias and Antiarrhythmic Drugs. (Budapest: Akademiai Kiado, 1971) pp. 24-92.

Tamargo, J.. Moe, B. and Moe, G.K.: Interaction of sequential stimuli applied during the relative refractory period in relation to determination of fibrillation threshold in the canine ventricle. Circ. Res. 37: 534-541, 1975 .

Thompson, P.L. and Lown, B.: Sequential R/T pacing to expose electrical instability in the ischemic ventrical (abstr). Clin. Res. 20: 401, 1972.

Thorp, R.H. and Cobbin, L.B.: Cardiac stimulant Substances. (New York: Academic Press, 1967) pp $156-167$.

Vanremoortere, E. and Hauters, E.: Fibrillation threshold curves and antiarrhythmic drugs. Arch. int. Pha rmacodyn. 176: 476-479, 1968 .

Van Tyn, R.A. and Mac Lean, L.D.: Ventricular fibrillation thresholds. Amer. J. Physiol. 201: $457-461,1961$.

Vaughan Williams, E.M. and Szekeres, L.: A comparison of tests for antifibrillatory action. Brit. J. Pharmacol. 17: 424-432, 1961 .

Verrier, R.L., Calvert, A, Lown, B. and Axelrod, P.: Effect of acute-biood pressure elevation on the ventricular fibrillation threshold. Amer. J. Physiol. 226: 893-897, 1974 .

Verrier, R.L., Calvert, A. and Lown, B.: Effect of posterior hypothalamic stimulation on ventricular fibrillation threshold. Amer. J. Physiol. 228: $923-927,1975$.

Vitello, M.V. and Woods, S.C.: Caffeine, preferential consumption by rats. Pharmacol. Biochem. and Behavior 3: 147-149, 1975.

Vulpian, A.F.E.: Note sur les effets de faradization directe des ventricules du coeur chez le chlen. Arch. Physiol. Norm. Path. 2nd serie. 1: 975, 1874. 
Waldeck, B.: Sensitization by caffeine of central catecholamine receptors. J. Neural Transmission 34: $61-72,1973$.

Wegria, R. and Wiggers, C.J.: Factors determining the production of ventricular fibrillation by direct currents. Amer. J. Physiol. 131: 104-118, 1940a.

Hegria, R. and Wiggers, C.J.: Production of ventricular fibrillation by alternating currents. Amer. J. Physlol. 131: 119-128, 1940b.

Wegria, R.. Moe, G.K. and Wiggers, C.J.: Comparison of the vulnerable periods and fibriliation thresholds of normal and idioventricular beats. Amer. J. Physiol. 133: 651-657, 1941 .

Wellens, D. and Wauters, E.: Modification of ventricular fibrillation thresholds after sympatholytic drugs in the dog. Arch. int. Pharmacodyn. 198: 355-371, 1972.

West, T.C. and Lauda, J.F.: Minimal mass required for induction of a sustained arrhythmia in isolated atrial segments. Amer. J. Physiol. 202: 232-236, 1962.

Westfall, D.P. and Fleming W.W.: Sensitivity changes in the dog heart to norepinephrine, calcium and aminophylline resulting from pretreatment with reserpine..J. Pharmacol. Exp. Ther. 159: 98-106, 1968.

Wiggers, C.J. and Wegria, R.: Ventricular fibrillation due to single, localized induction and condenser shocks applied during the vulnerable phase of ventricular systole. Amer. J. Physiol. 128: 500-505, 1940 .

Wiggers, C.J. and Wegrla, R.: Quantitative measurement of the fibrillation thresholds of the mammalian ventricles with observations on the effect of procaine. Amer. J. Physiol. 131: 296-308, 1940b.

Wiggers, C.J., Wegria, R. and Pinera, B.: The effects of myocardial ischemia on the fibrillation threshold The mechanism of spontaneous ventricular fibrillation following coronary occlusion. Amer. J. Physiol. 131: $309-316,1940$.

Wolman, W.: Instant and decaffenated coffee. J. Amer. Med. Assoc. 159: 250, 1955. 
page 124

Yoon, M.S., Han, J., Goel, B.G. and Creamer, P.: Effect of procainamide on fibrlilation threshold of normal and ischemic ventricles. Amer. J. Cardiol. 33: $238-242,1974$. 


\section{APPENDIX}

\section{List of References \\ Used in Tables $|-|||$}

1. George et al. 1974

2. Vanremoortere and Wauters, 1968

3. Horowltz et al, 1975

4. Bacaner, 1968

5. Wellens and Wauters, 1972

6. Aravalnakshan and Gettes, 1975

7. Rotenberg et al.e 1977

8. Vaughan Will lams and Szekeres, 1961

9. Shinohara, 1968

10. Harrison et al. 1974

11. Wegria and Nickerson, 1942

12. Han et al.e 1964

13. Hellenbrecht and Gortner, 1975

14. Lubbe et al.e 1975

15. Hoff and Nahum, 1934

16. Desilva et al 1977

17. Shen and simon, 1938

18. Verrier et al 1974

19. Das and sinha, 1972

20. Allen et alee 1975

21. Yoon et al.e 1974

22. Moore and Spear, 1975

23. Skinner et al e 1975

24. Schwartz et ale 1976

25. Garza et al.e 1974

26. Gerst et ale 1966

27. Murnaghan, 1975

28. Wiggers et al 1940

29. Shumway et ale 1957

30. Han, 1969

31. Axel rod et al. 1975

32. Han et ale $1966 \mathrm{~b}$

33. Bellet et al. 1972

34. Han and Moe, 1964

35. Levy, 1911

36. Scherf, 1947

37. Armitage et al 1957

38. Grumbach et ale 1954

39. Karki, 1953

40. Boehm, 1875

41. Dikshit, 1934

42. Lown et al.e 1977 